\title{
Enerjide Optimizasyon Uygulamaları: Bir Literatür Araştırması
}

\author{
Optimization Models in Energy: A Literature Review
}

Beyzanur ÇAYIR ERVURAL 1*, Bilal ERVURAL ${ }^{2}$, Ramazan EVREN

\begin{abstract}
ÖZET
Enerji ülkeler için öncelikli kalkınma hedefleri arasındadır. Değişen çevre koşulları ve iklim şartları enerji ihtiyacının karşılanması noktasında ülkeleri çıkmaza sokmaktadır. Hızla artan enerji talebinin karşılanmasında enerjinin düşük maliyetli, sürdürülebilir ve güvenilir olması gerekmektedir. Enerji bütün sektörlerin vazgeçilmez girdisi olduğundan bu alanda yapılacak iyileştirmeler tüm sektörleri doğrudan etkiler. Dolayısıyla bu alanda yapılacak optimizasyon uygulamalarına intiyaç vardır. Enerji disiplinler arası bir uygulama alanına sahiptir. Bu yüzden farklı mühendislik problemlerinin entegrasyonu optimizasyon uygulamalarını gerekli kılmaktadır. $\mathrm{Bu}$ çalışmada enerji sahasında yapılan araştırmalar endüstri mühendisliği bakış açısıyla incelenerek enerjide optimizasyon gerekliliği vurgulanmıştır. Bu açıdan enerji problemleri karar seviyesi, uygulama alanı ve enerji türü bakımından sınıflandırımış ve ele alınan optimizasyon problemleri model yapıları ve çözüm yöntemleri açısından incelenmiştir. Bu çalışmanın gelecek araştırmalar için alt yapı oluşturacağı düşünülmektedir.
\end{abstract}

Anahtar Kelimeler: Enerji, yenilenebilir enerji kaynakları, optimizasyon, karar verme.

\begin{abstract}
Energy is one of the priority development objectives for the countries. Changing environmental and climate conditions force countries to meet their energy needs. Energy should be low-cost, sustainable and reliable to meet the rapidly rising demand. Since energy is a substantial input for all sectors, improvements in this area directly affect the sectors. Therefore, there is a need for optimization applications to be performed in this subject. Energy has an interdisciplinary application area, so the integration of different engineering problems requires optimization applications. In this study, optimization problems of energy field are discussed, and energy problems are classified by decision level, application area and energy type. In addition, the related literature is analysed with regard to model structures and solution methods. The paper provides an overview of the applications of energy optimization techniques in order to guide researchers studying in this area.
\end{abstract}

Keywords: Energy, renewable energy sources, optimization, decision making..

\section{Gíriş}

Enerji planlaması, yerel, bölgesel hatta küresel enerji sisteminin geleceğine rehberlik etmek amacıyla uzun soluklu politikaların geliştirilme sürecidir. Küreselleşme, hızla nüfusun artması, ülkelerin kalkınmak için sanayileşme çabaları sonucunda enerjiye ve doğal kaynaklara olan talep büyük artış sergilemektedir. Uluslararası Enerji Ajansı dünya birincil enerji talebinin 2007-2030 yılları arasında $\% 40$ oranında artacağına işaret etmektedir. Yıllık ortalama \%1,5 düzeyinde talep artışına karşılık gelen bu durumun dünya birincil enerji talebi 2007 yılındaki 12 milyar Ton Eşdeğer Petrol (TEP) düzeyinden 2030 yılında 16,8 milyar TEP düzeyine ulaşacağı yapılan araştırmalarla gösterilmektedir.

Enerji üretim kaynakları ana enerji kaynakları ve yenilenebilir(alternatif) enerji kaynakları şeklinde sınıflandırılmaktadır. Ana enerji kaynaklarında su enerjisine hidrolik, kömür, petrol ve gaz enerjisine termik, çekirdek enerjisine de nükleer enerji denilmektedir. Yenilenebilir enerji kaynakları, alternatif enerji kaynağı olarak da kabul edilebilir ve şu şekilde örneklendirilmektedir: Rüzgar, güneş, jeotermal, hidroelektrik, biyokütle, dalga gücü, güneş pilleri. Burada dikkat edilmesi gereken nokta alternatif enerji kaynaklarının ana enerji kaynakları yerine ikame edilememesidir. Çünkü ana enerji kaynaklarının en önemli kriterinden birisi olan "süreklilik" ilkesini alternatif enerji kaynakları sağlamakta başarısız olabilmektedir.

\footnotetext{
1*istanbul Teknik Üniversitesi, Endüstri Mühendisliği Bölümü, cayirb@itu.edu.tr 
Ana enerji kaynaklarının oluşturduğu sera gazları, küresel ısınmaya yol açmaktayken alternatif enerji kaynaklarında ise maliyetin yüksek oluşu, bilinmeyen risk düzeyleri ve uygun tesis yerinin seçimi gibi problemler belirsizliklere yol açmaktadır. $\mathrm{Bu}$ sorunlar ülkelerin öz kaynaklarını etkin biçimde kullanmamasına yol açmakta ve enerjide optimizasyon uygulamalarına intiyaç duyulmaktadır. Günümüzde sürdürülebilirliğin sağlanması ve doğal dengenin korunması enerji sistemlerinin optimal şekilde planlanması (işlenmesi, dağıtılması ve kullanılması) ile mümkündür (TMMOB, 2012).

Jebaraj ve Iniyan (2006) enerji planlama modelleri hakkında geniş bir literatür çalışması yapmışlar ve tahmin modelleri, enerji arz-talep modelleri, optimizasyon modelleri ve emisyon azaltma modelleri olarak kronolojik olarak değerlendirmişlerdir. Enerji planlamasında yer alan üç modelden bahsetmişlerdir. Kleinpeter (1995) toplam enerji talebine karar vermede kullanılan göstergeleri şöyle sunmuştur:

i. Enerji talep modelleri: enerji talebini sektör bazında endüstriyel, konutsal ve ulaştırma sektörlerinde araştırmışlardır.

ii. Enerji arz modelleri: öngörülen bir değerde enerji talebini tahmin etmektedir.

iii. Bir diğeri de, enerji arz ve talebini birlikte ele alan modellerdir.

Enerji konusunda ülkelerin yaptıkları ciddi yatırımlar bu sektörün öncelikli olduğunu göstermektedir. Çoğu enerji kaynağı iklim şartlarına bağlıdır bu yüzden tasarım, planlama ve kontrol süreçlerinde optimizasyon yöntemleri kullanılmaktadır.

Bu çalışmada ele alının enerji problemlerinin matematiksel modelleri incelenerek problemlerin güçlüğü, modelin uygulanabilirliği ve içerdiği kısıtlarla enerji optimizasyon modelleri sınıflandırılmıştır. Literatürde yer alan çalışmaların çoğunlukla yenilenebilir enerji planlaması, elektrik kullanım planlaması, en uygun enerji alternatifi seçimi, enerji kaynağı atanması, enerji yönetim inşası ve proje planlama konuları üzerine olduğu görülmektedir. $\mathrm{Bu}$ açıdan bu alanla ilgili çalışmalar incelendiğinde çoğunlukla karar verme konusunda araştırmaların yer aldığı gözlenmiştir. Enerji kararları alınırken uygulanan tek/çok amaçlı karar verme, çok kriterli karar verme, karar destek sistemi ve belirsizlik altında karar verme yöntemlerini ele alan çalışmalar incelenmiştir. Analitik Hiyerarşi Süreci (AHS) en yaygın kullanılan Çok Kriterli Karar Verme (ÇKKV) tekniğidir. Daha sonra PROMETHEE, ELECTRE ve TOPSIS yöntemleri gelmektedir (Zhou vd., 2006). Enerji sektöründe uygulanan optimizasyon yöntemleri her enerji tipi için ayrı ayrı ele alınarak incelenmiştir. Çalışmalarda geleneksel yaklaşımlar ve meta sezgisel yaklaşımlar kullanılmaktadır ancak hesaplama karmaşasından dolayı geleneksel optimizasyon yöntemleri ile optimal çözümü bulmak oldukça zordur. Meta sezgisel yöntemlerin çoğunlukla kullanılmasının nedeni enerji problemlerinin NP-zor olması ve karmaşık yapıdaki modeller için makul sürede çözüm sunmasıdır. Bu çalışmada literatürde yapıımış çalışmalar ele alınan başlıklarla incelenerek eksiklikler tespit edilmiştir. Çalışmanın bu alanda çalışan araştırmacılar ve gelecek çalışmalar için kaynak olacağı öngörülmektedir.

\section{ENERJI SEKTÖRÜNDE OPTIMIZASYON}

Çoğu enerji kaynağı iklim şartlarına bağlıdır bu yüzden enerjinin tasarım, planlama ve kontrol aşamasında optimizasyon yöntemlerinin kullanılması gerekmektedir. Enerji sektörü disiplinler arası bir uygulama alanına sahiptir. Farklı mühendislik problemlerinin entegrasyonu optimizasyon uygulamalarını gerekli kılmaktadır. Enerji problemleri karmaşık, belirsizliği yüksek ve çok fazla paydaşa hizmet vermeye çalışmaktadır. Kısıtlı şartlar altında karar verilir. Çok sayıda karar değişkeni ve parametre içerdiğinden teknik karmaşıklığı yüksek ve çözümü zor problemlerdir.

Enerji problemlerinde bir çok amaç aynı zamanda iyileştirmeye çalışıldığından iyi bir optimizasyon sahasıdır, dolayısıyla yöneylem araştırması uygulama alanına girmektedir. Enerjide optimizasyon çalışmaları giderek artan trend sergilemektedir (Baños vd., 2011). Enerji verimliliği artırma, enerjide karar verme, enerji yatırım ve planlaması, enerji tesis yeri seçimi, en uygun enerji alternatifi seçilmesi, enerji kaynağı atanması, enerji yönetim inşası ve proje planlama, enerji kaynağının güvenirliği gibi problemler literatürde enerjinin optimizasyon uygulamaları kapsamında incelenmektedir. Dünya genelinde enerjiye olan talebin hızlı artışı,

i. dağıtım ağlarının genişletilmesinde

ii. uygun maliyetlerle yenilenebilir enerji kaynaklarının uzun dönemli planlanmasında ve tasarımında optimizasyon çalışmalarına intiyacı doğurmaktadır.

Şekil 1'de verilen optimizasyon yöntemleri genel olarak enerjide kullanılan yöntemler olup detayları ilerleyen bölümlerde açıklanacaktır. 


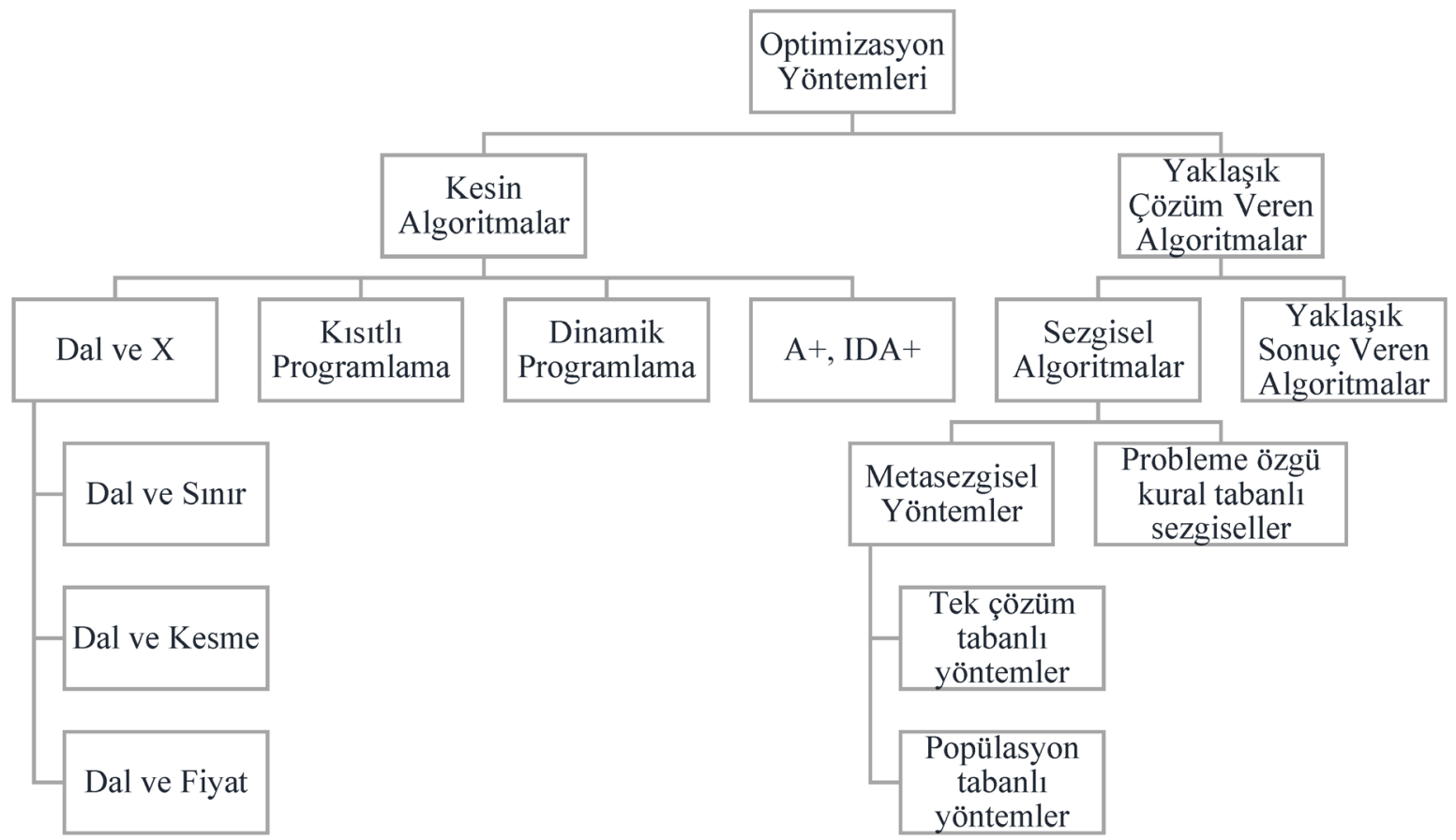

Şekil 1: Optimizasyon yöntemleri (Talbi, 2009)

\section{ENERJI PROBLEMLERININ SINIFLANDIRILMASI}

Bu bölümde enerji problemleri enerji türlerine, uygulama alanlarına ve karar seviyelerine göre sınıflandırılmıştır.

\subsection{Enerji Türüne Göre Sınıflandırma}

Enerji problemleri enerji türlerine göre altı ana kategoride ele alınmıştır (Zhou vd., 2006). Bunlar;

- Genel: Enerji tedarik ve talebine odaklanır, özel bir enerji kaynağı ile ilgilenmez.

- Katı yakıtlar: Başlıca katı yakıtlar odun ve maden kömürleridir. Linyit, taş kömürü, kok kömürü ve antrasit diğer katı yakıtlardan bazılarıdır.

- Petrol/Gaz: Petrol ve petrol ürünleridir. Gaz yakıtlar, sıvılaştırılmış petrol gazları (LPG), doğal gaz ve hava gazı gibi yakıtlardır.
- Yenilenebilir Enerji Kaynakları: Temel yenilenebilir enerji kaynakları rüzgar, güneş, jeotermal, hidrolik ve biyokütledir.

- Nükleer Enerji Kaynakları: Nükleer reaktörler nükleer enerjiyi elektrik enerjisine dönüştüren sistemlerdir. Temel olarak fisyon sonucu açığa çıkan nükleer enerji, nükleer yakıt ve diğer malzemeler içerisinde ısı enerjisine, bu ISI enerjisi de kinetik enerjiye ve daha sonra da jeneratör sisteminde elektrik enerjisine dönüştürülür.

- Elektrik:Mekanik veya kimyasal enerjinin veya ISI enerjisinin elektriğe dönüştürülmesiyle elde edilen ve tüketicilerin kullanımına sunulan enerjidir.

Şekil 2'de enerji türlerine göre yapılan çalışmaların payları verilmiştir. 


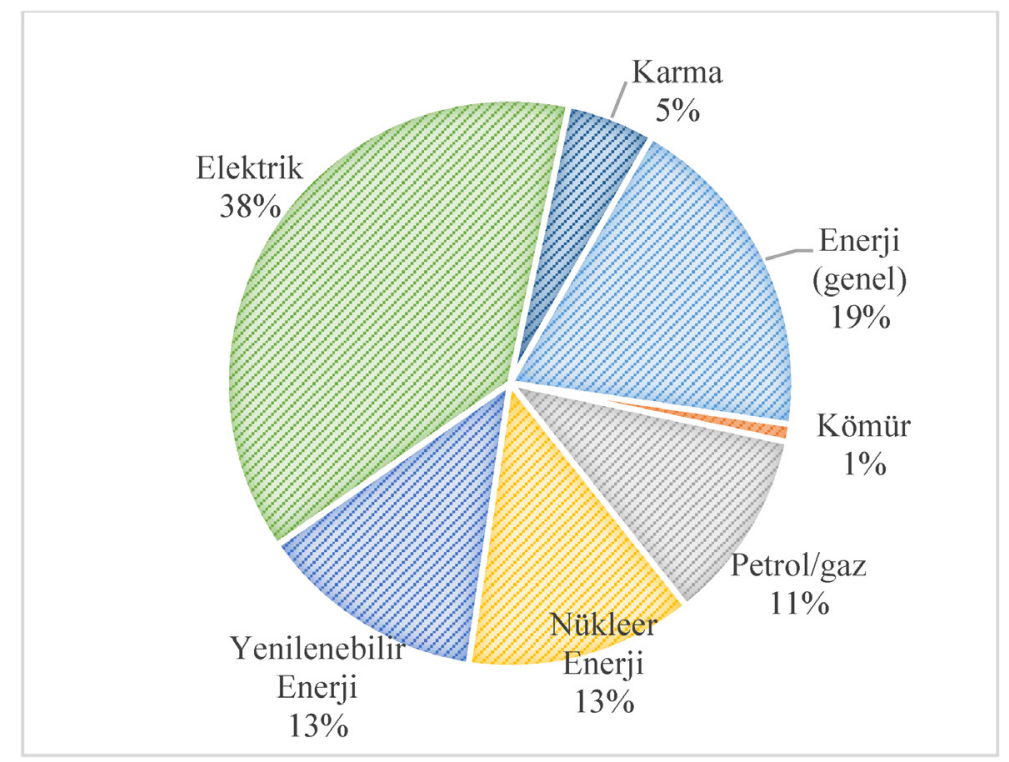

Şekil 2: Enerji türlerine göre yapılan çalışmalar (Zhou vd., 2006)

\subsection{Uygulama Alanına Göre Sınıflandırma}

Uygulama alanı bakımından Enerji yedi ana başlık altında ele alınmaktadır (Zhou vd., 2006).

- Enerji politikası analizi: Enerji politikası formülasyonu ve gelişimine rehberlik eden enerji sistem değerlendirmesidir. Enerji sistemleri değerlendirme, enerji politikasında kamu borcu, enerji dönüşüm stratejileri, enerji kaynağı atama konularını kapsar.

- Elektrik güç planlaması: Güç üretimi esnasındaki stratejik planlama konularıyla ilgilenir. Güç iletimi ve dağıtımı, güç üretimi genişletme planlaması, elektrik iletim ağı, güç dağıtım planlaması konularıyla ilgilenir.

- Teknoloji seçimi ve proje değerlendirme: Enerjiyle ilgili yatırım projelerinin değerlendirilmesi, enerji teknolojilerinin seçimi ve değerlendirilmesini içerir. Elektrik tedarik projelerinin seçimi ve değerlendirilmesidir.

- Enerji fayda işlemleri ve yönetimi: Enerji endüstrisindeki operasyonel konularla ilgilenir. Enerji teklifi, fiyatlandırma, santral yer seçimi ve enerji şirketlerinin yönetimi konuları bu kapsamda değerlendirilir.

- Enerjiyle alakalı çevre politikaları analizi: İklim politikası değerlendirme, yeşil-ev ısınma üzerine kamuoyu araştırmaları, hava kirliliği kontrol politikası gibi konularla ilgilenmektedir.
- Enerjiyle ilgili çevresel kontrol ve yönetim: Katı atık yönetimi, atık depoları değerlendirme, ana kalkınma projeleriyle ilgili çevresel atıklar bu kapsamda yer almaktadır.

- Diğer: Yukarıda yer alan konulara girmeyen problemlerdir.

\subsection{Karar Seviyesi Bakımından Sınıflandırma}

Karar seviyesi bakımından enerji problemleri iki ana başlık altında incelenebilir (Zhou vd., 2006).

- Stratejik/politik (S/P) Makro konular: Enerji yatırım kararı, enerji politikası analizi, enerji dönüşümü gibi uzun dönemli kararları içeren çalışmalardır.

- Operasyonel/taktiksel (O/T) Operasyonel konular: Kısa vadeli kalkınma hedefleri, teklif, fiyatlandırma gibi çalışmalar bu kapsamda değerlendirilir.

\section{ENERJI SISTEM MODELLERININ SINIFLANDIRILMASI}

Literatürde enerji sektöründe yapılan çalışmalar arasında en yaygın olanları enerji planlama modelleri, enerji kaynakları dağıtım planlaması ile ilgili olanlardır. Genellikle karma tamsayılı doğrusal programlama yaklaşımıyla ele alınmışlardır. Bu bölümde enerji sektöründe kullanılan matematiksel modeller ile enerji kararlarının verilmesinde kullanılan karar verme modellerinden bahsedilmiştir. Literatürde yapılan çalışmalar incelenerek Şekil 3'te enerji sistem modelleri için bir sınıflandırma önerilmiştir. 


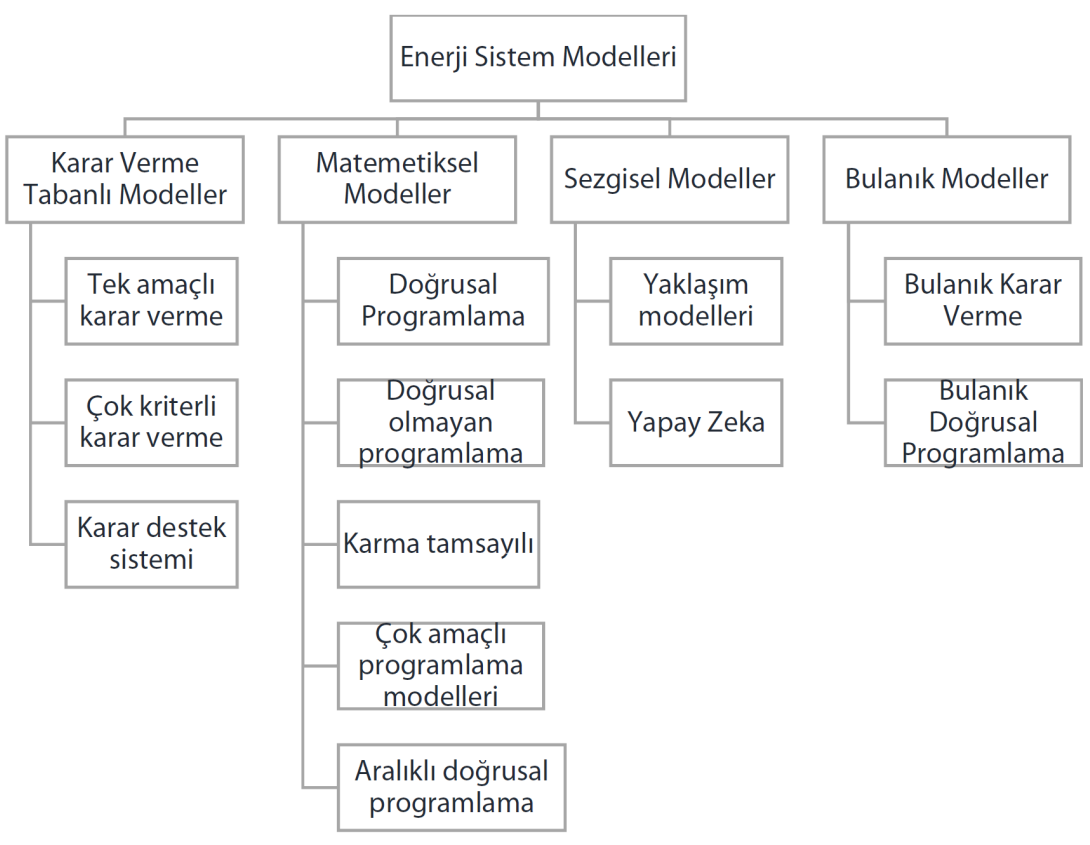

Şekil 3: Enerji sistem modellerinin sınıflandırılması (Baños vd., 2011; lqbal vd., 2014)

Tablo 1'de yenilenebilir enerji problemlerinde yer alan girdiler, kısıtlar ve amaç fonksiyonları gösterilmiştir (lqbal vd., 2014).

Tablo 1: Yenilenebilir enerjide yaygın kullanılan girdiler, kısıtlar ve amaçlar (lqbal vd., 2014)

\begin{tabular}{|c|c|}
\hline Girdiler & Çözümü araştırılan konular \\
\hline Yenilenebilir enerji kaynak, birim, tip ve sayısı & Toplam üretilen enerji \\
\hline Kullanılan arazi miktarı & Üretim birim kapasite ve sayısı \\
\hline Atmosfer koşulları & Toplam yatırım \\
\hline Yenilenebilir enerji kaynağı birim teknolojisi & Yenilenebilir enerji kaynağının ömrü \\
\hline Operasyon çeşidi & İşlem ve bakım maliyeti \\
\hline İşlem ömrü & Yenilenebilir enerji kaynağının güvenirliği \\
\hline Etkinlik & Beklenen kar \\
\hline Operasyon ve bakım maliyeti & Tahmin edilen arazi kullanımı \\
\hline Meteoroloji şartları & Yenilenebilir enerji kaynağı birimlerinin en iyi karışımı \\
\hline Yenilenebilir enerji kaynak birimlerinin coğrafi yerleşimleri & Yenilenebilir enerji kaynağı açılımı/yerleşimi \\
\hline Özel girdilerle ilgili yenilenebilir enerji kaynakları & Yenilenebilir enerji kaynağı ile ilgili özel değişkenler \\
\hline Kısıtlar & Amaçlar \\
\hline Çevresel/atmosfer kısıtları & En küçükleme (Minimizasyon) \\
\hline Talep/yük yönetim kısıtları & Sistem toplam maliyeti \\
\hline Ekonomik/bütçe kısıtları & Birim başına üretilen enerji maliyeti \\
\hline Pillerin depolama kapasitesi & Arazi alanı \\
\hline Şarj ve boşaltma kısıtları & Yatırım \\
\hline Karbondioksit emisyon kısıtları & Toplam bakım maliyeti \\
\hline Sosyal/düzenleyici kısıtlar & Gürültü ve kirlilik emisyonu \\
\hline Güç kaybı olasılık kısıtı & Enerji tedariki kayıp olasılığı \\
\hline Bileşenlerin yaşam ömrü kısıtı & En büyükleme (Maksimizasyon) \\
\hline Yenilenebilir enerji kaynak birimlerinin güç oran kısıtı & Termal verimlilik \\
\hline Dağıtım hatlarında maksimum güç akış limit & Toplam güç üretimi \\
\hline Yenilenebilir enerji kaynakları için kullanılan arazi boyutu & Sistem güvenirliği \\
\hline Üretim birimleri & Kar \\
\hline Enerji kısıt maliyeti & Yaşam süresi \\
\hline \multirow[t]{2}{*}{ Yenilenebilir enerji kaynağı ile ilgili özel kısıtlar } & Toplam gelir \\
\hline & Yenilenebilir enerji kaynaklarıyla ilgili özel amaçlar \\
\hline
\end{tabular}




\subsection{Karar Verme Tabanlı Modeller}

Karar verme tabanlı modeller tek amaçlı karar verme, çok kriterli karar verme ve karar destek sistemleri olarak sınıflandırılabilir (Zhou vd., 2006).

- Tek amaçlı karar verme : Tek amaç altında mevcut alternatiflerin değerlendirilmesi için bir yöntemler sınıfıdır.

- Çok kriterli karar verme: Birden fazla kriter altında karar vericilerin alternatifleri sıralamasına veya arasından en iyiyi seçmeye yardımcı olur. Kararlar birbiriyle çelişen çok sayıda kriter arasından uzlaşılarak yada ödünleşmeye dayanılarak verilir. Çok amaçı ı karar verme (ÇAKV) ve çok ölçütlü karar verme (ÇÖKV) bu model türünün iki alt sınıfıdır.

- Karar Destek Sistemleri (KDS): Modelleri veri tabanlarını ve diğer karar yardım araçlarını bütünleştiren etkileșimli esnek ve uyarlanabilir yazılım araçlarını ifade eder. KDS çözümü güç yapılandırılmamış ve karmaşık karar problemlerinin çözümüne destek sağlar. Geleneksel KDS de uygun parametre ve modelleri seçmek için kullanıcılar uzman bilgisine bağımlıdır. Şekil 4'te karar verme tabanlı modeller sınıflandırılmıştır.

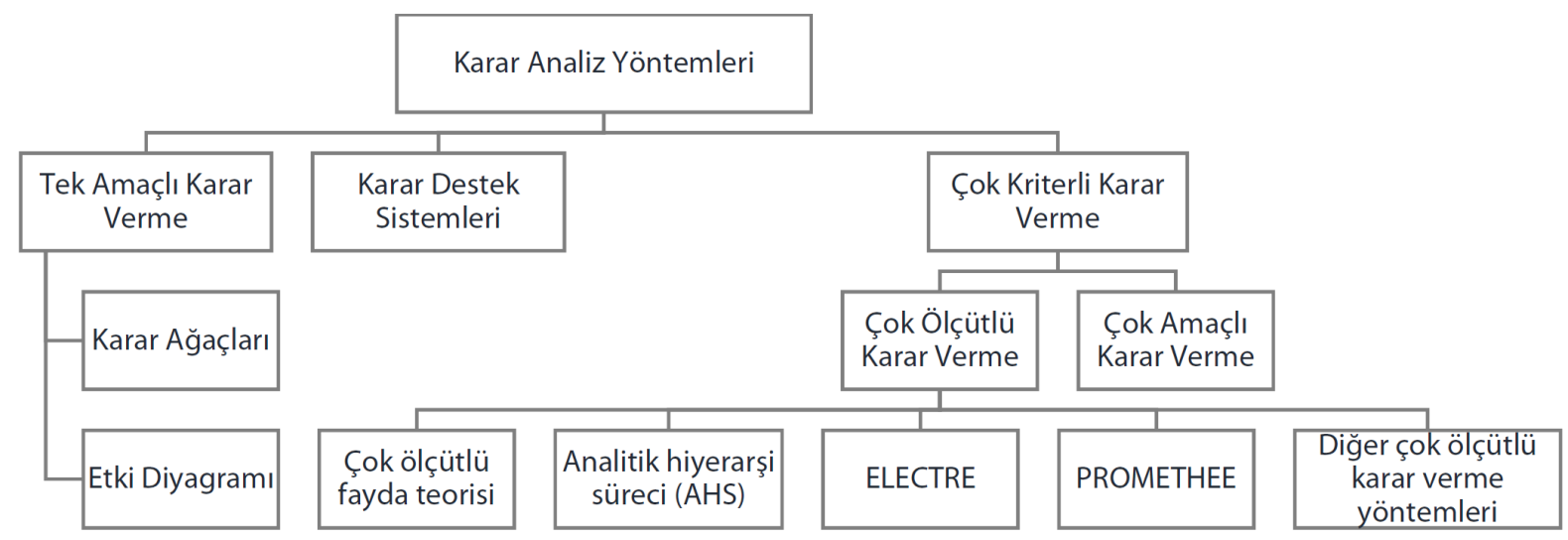

Şekil 4: Karar analizi metotlarının sınıflandırılması (Zhou vd., 2006)

\subsection{Matematiksel Modeller}

Modeller sınıflandıııldığında çalışmalarda yer alan en yaygın modeller şunlardır (Taha, 2007):

- Doğrusal programlama modelleri: Bir doğrusal amaç fonksiyonun doğrusal eşitlikler ve eşitsizlikler kısıtlamaları ile optimizasyon yapılmasıdır.

- Doğrusal olmayan modeller: Karar modelinin kısıtlarından en az biri veya amaç fonksiyonunun doğrusal olmadığı durumlar için geliştirilen modellerdir.

- Karma tamsayılı modeller: Modeldeki değişkenlerin bazıları tamsayı, bazıları kesirli ise karma tamsayılı modelleme kapsamında değerlendirilir.

- Çok amaçlı programlama modelleri: Birden çok ve birbiriyle çelişen amaçları içeren model türüdür. ÇAKV karar vericilere farklı amaçlar için farklı faydalar arasında ödünleşmeyi esas alır ve öncelikli olanı seçer (Savic, 2002).
Çoğu gerçek mühendislik problemlerinde genellikle maliyetin azaltılması, performansın artırılması, güvenirliğin artırılması gibi çoklu amaçlar yer alır. Bu noktada ÇAKV artan karmaşıklıktaki enerji yönetimi problemlerinde etkin çözümler sunar. Scopus veritabanı incelendiğinde son yıllarda araştırmacıların ÇAKV'e olan ilgisinin arttığını görebiliriz (Şekil 5).

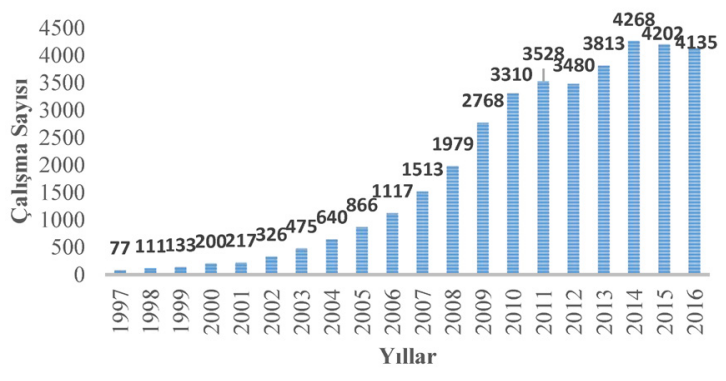

Şekil 5: Son 20 yılda ÇAKV konusunda yapılan çalışmalar (Scopus, 2016) 
- Aralıklı doğrusal programlama: Model katsayılarının tümünün veya bir kısmının kapalı reel sayı aralıkları olarak verilmesi halinde optimal çözüme ulaşmaktadır.

- Pareto optimizasyon yaklaşımlar: Pareto temelli yaklaşımlar birden fazla amacın olduğu problemler için baskın ve baskın olmayan çözümleri seçim şemasının pareto optimalliğine dayandırarak uygun çözüm sunan yaklaşımlardır. ilk olarak Goldberg tarafından önerilmiştir (1989). Şekil 6'da pareto optimizasyon yaklaşımı gösterilmiştir.

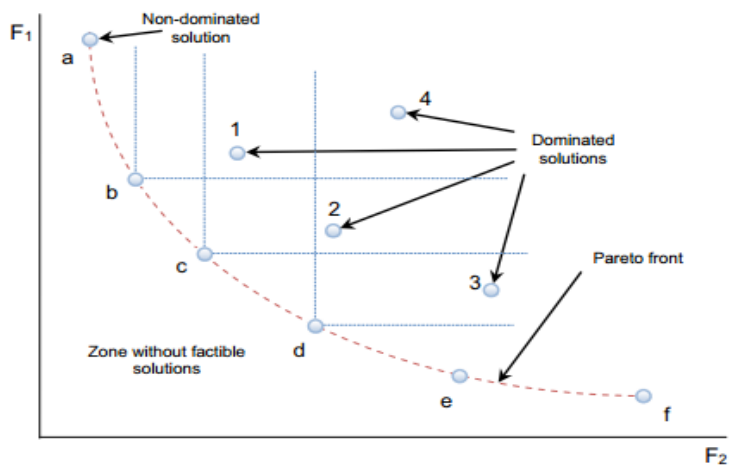

Şekil 6: Çok amaçlı evrimsel bir algoritma için pareto optimizasyon yaklaşımı (Dufo-López vd., 2011)

Matematiksel yöntemleri çözüm yöntemleri açısından dört başlıkta inceleyebiliriz (Taha, 2007; Turkay, 2006):

- Simpleks yöntemi: Grafik yöntemin uygulanamayacağı çok değişkenli doğrusal programlama problemlerinin çözümünde yaygın biçimde kullanılan bir uç nokta arama algoritmasıdır.

- Lagranj gevşetmesi: Çözümü güç tamsayılı doğrusal programlama problemlerinde bazı kısıtların duali alınarak bunların lagranj çarpanı olarak amaç fonksiyonuna ceza değeri olarak ekleyen modellerdir.

- Dinamik programlama: Dinamik programlama, $\mathrm{n}$ değişkenli bir problemin optimum çözümünü problemi $\mathrm{n}$ aşamaya ayrıştırarak ve her aşamada tek değişkenli bir alt problemi çözerek belirler.

- Dal sınır algoritmaları: Dal-sınır algoritması tamsayılı değişkenlerin alabileceği tamsayılar kümesindeki en küçük ve en büyük değerler arasında herhangi bir reel sayıyı alabilecek şekilde gevşetilmesiyle elde edilen problemlerin çözümü esasına dayanır.

\subsection{Sezgisel Modeller}

Optimizasyonda kesin yöntemlerin tersine sezgisel yöntemler optimal çözümü garanti etmezler. Sezgisel yöntemlerin kullanılmasında bazı nedenler söz konusudur (Bakır ve Altunkaynak, 2003; Talbi, 2009):

- Sezgisel yöntemler kesin bir formülasyonu ve çözüm yöntemi olmayan problemler için kullanılır.

- Problem için kesin çözüm yöntemleri olsa bile büyük ölçekli problemler için yoğun hesaplama gereklilikleri ve çözüm zamanı bakımından sıkıntı söz konusu olduğunda, özellikle gerçek zamanlı uygulamalarda sezgisel yöntemler tercih edilebilir.

- Sezgisel yöntemler aynı zamanda dal ve sınır çözüm yönteminde optimal çözümün sınırlarını hesaplamak için kullanılabilir.

Literetür incelendiğinde enerji alanında Yapay Sinir Ağları (YSA), Genetik Algoritmalar (GA), Parçacık Sürü Optimizasyonu (PSO), Tavlama Benzetimi, Karınca Koloni Algoritması (KKA) ve hibrid modellere rastlanmaktadır.

\subsection{Bulanık Mantık Temelli Modeller}

Bulanık mantık, bulanık küme teorisine dayanan bir matematiksel disiplindir. Bulanık mantık doğrusal olmayan, karmaşık, modellemesi güç ve bilgilerin, niteliklerin belirsiz veya kesin olmadığı durumlarda kullanılan başarılı bir metottur (Tiryaki ve Kazan, 2007). 1965 yılında Lotfi A. Zadeh tarafından yayınlanan bir makalede bulanık mantık veya bulanık küme kuramı adı altında ortaya konulmuştur. Kullanılan modeller şöyledir (Suganthi vd., 2015):

i. Bulanık modeller (a) bulanık delphi (b) bulanık regresyon (c) bulanık gri tahmin (d) bulanık AHS (e) bulanık Analitik Ağ Süreci (AAS) (f) bulanık kümeleme

ii. Hibrid modeller (a) sinirsel bulanık, uyarlanabilir sinirsel bulanık çıkarım sistemi (ANFIS) (b) bulanık GA, sinirsel bulanık GA (c) bulanık uzman sistem, sinirsel bulanık uzman sistem (d) bulanık KDS (e) bulanık Veri Zarflama Analizi (VZA), sinirsel bulanık VZA

iii. Çok kriterli karar modelleri (a) bulanık VIKOR (b) bulanık TOPSIS (c) bulanık destek vektör makinesi (d) bulanık PSO (e) bulanık arı kolonisi 
optimizasyonu (f) bulanık guguk kuşu arama optimizasyonu (g) bulanık kuantum PSO (h) bulanık KKO.

\subsection{Belirsizlik Modelleri}

Şekil 7'de belirsiz parametreler için geliştirilmiş bazı belirsizlik modelleme metotları verilmiştir. $\mathrm{Bu}$ yöntemler arasındaki temel fark, girdi parametrelerinin belirsizliği tanımlamak için kullanılan farklı tekniklerle uyumudur. Örneğin, stokastik yöntemler olasılık yoğunluk fonksiyonunu kullanırken bulanık mantık belirsiz bir parametreyi tanımlayan üyelik fonksiyonlarını kullanır. Bunların benzerliği, girdi parametrelerinin modelin çıktıları üzerindeki etkinliğini ölçebilmektir.

Olasılıksal yaklaşım: Stokastik programlamada ilk olarak Dantzing (1955) tarafından önerilmiştir.
Bu modelin girdi parametreleri, bilinen bir olasılık yoğunluk fonksiyonu ile rastgele değişkenler olduğu varsayılmaktadır.

Olabilirsel yaklaşım: Lotfi A. Zadeh, 1965 tarafından tanıtılmıştır. Modelin girdi parametrelerini üyelik fonksiyonu kullanılarak açıklamıştır.

Hibrid olabilirsel-olasılıksal yaklaşımlar: Hem rassal hem olasılıklı parametreler modelde mevcuttur.

Bilgi boşluğu karar teorisi (IGDT): Yakov BenHaim,1980 tarafından ilk kez önerilmiştir. Metotta girdi parametreleri için olasılık yoğunluk fonksiyonu ya da üyelik fonksiyonu yoktur. Bilinmeyenler karşısında beklenen sonuçları maksimize edecek faaliyetlerin seçilmesiyle dinamikliği maksimize, başarısızığı minimize etmeyi amaçlamaktadır (BenHaim, 2006).

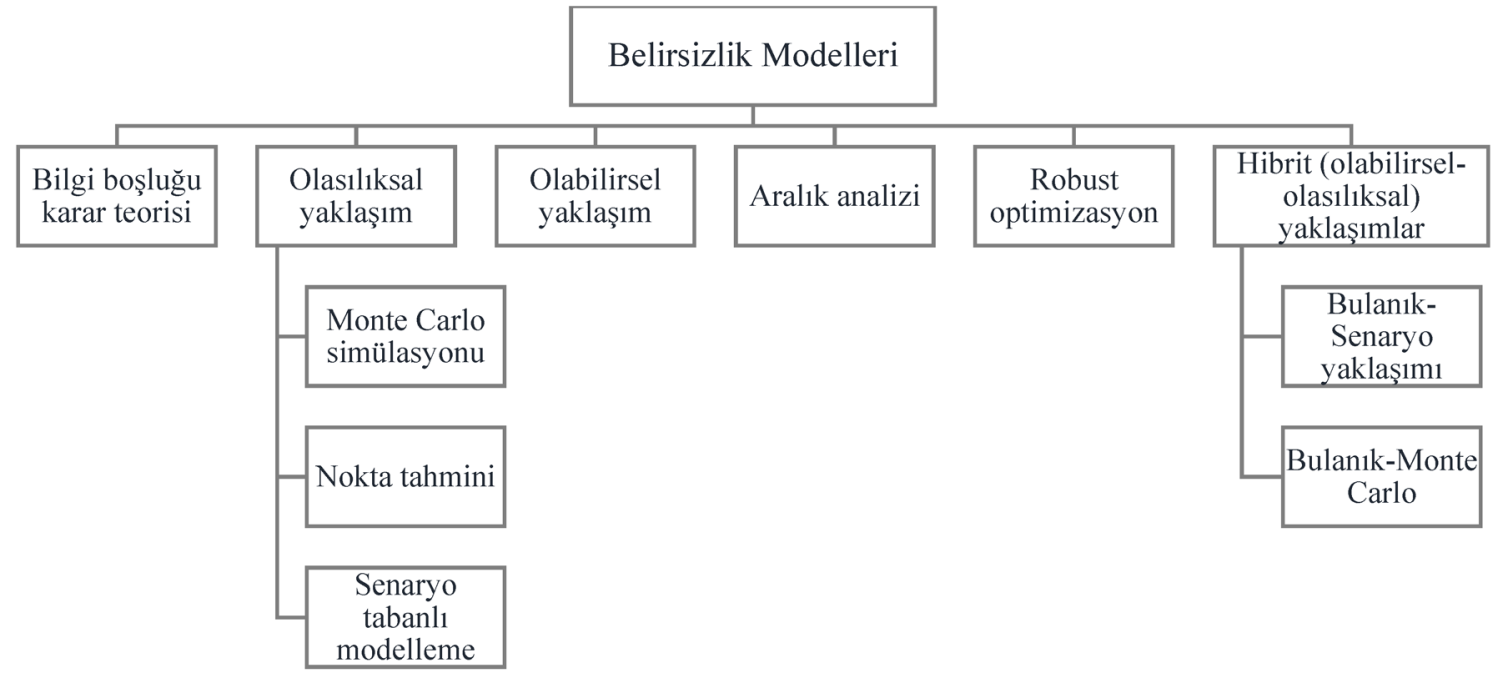

Şekil 7: Enerji sistemlerinde belirsizlik altında karar verme (Soroudi ve Amraee, 2013)

Robust optimizasyon: Belirsizlik kümeleri, girdi parametrelerinin belirsizliğini tanımlamak için kullanılır. Bu teknik kullanılarak belirli bir kümede verilen belirsiz parametrelerin kullanılmasıyla en kötü durum için elde edilen kararlar optimal kalmaktadır (Bertsimas ve Sim, 2004).

Aralık analizi: Ramon E. Moore, (1966) tarafından ilk kez tanıtılmıştır. Bilinen bir aralıkta belirsiz parametrelerin alınmasına dayanmaktadır. Olasılıksal modellemeye düzgün olasılık yoğunluk fonksiyonu ile benzemektedir.

Z Sayısı (Z-Number): Bulanık mantığın kurucusu Zadeh (2011) tarafından bulanık sayıların yeni bir sınıfı olarak ortaya konulmuştur. $Z=(A, B)$, klasik bulanık sayılarla karar verici sadece $Z$ 'nin davranışını tanımlayan A koşuluna sahip iken Z-sayısında A'ya ek olarak bilginin belirlilik (güvenilirlik) derecesi (B) kullanılmaktadır. Şekil 8'de görüldüğü gibi belirsizlik altındaki model trendleri geçmişten geleceğe yönelik sunulmuştur.

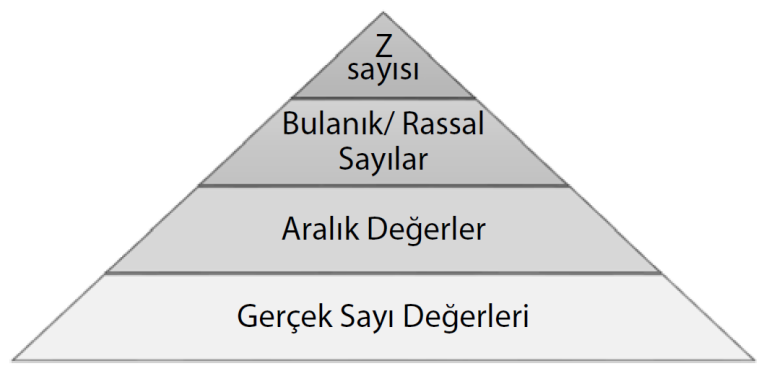

Şekil 8: Belirsizlik modelleri: Geçmiş, günümüz, gelecek (Lotfi A. Zadeh, 2011) 


\section{ENERJI KAYNAKLARINA GÖRE MODELLERIN SINIFLANDIRILMASI VE LITERATÜR ARAŞTIRMASI}

Bu bölümde enerji kaynaklarına göre modeller sınıflandırılmış ve literatür taraması sunulmuştur. Literatür araştırmasında incelenen çalışmalar her bir enerji kaynağı için farklı optimizasyon modellerini içerecek şekilde en çok atıf alan önemli çalışmalar arasından seçilmiştir.

Enerji kaynakları sahip olduğu pek çok avantaja rağmen üretimlerindeki süreksizlik gibi önemli bir dezavantaj sunmaktadır. Çoğu enerji kaynağı iklim şartlarına bağlıdır bu yüzden enerjinin tasarım, planlama ve kontrol aşamasında optimizasyon yöntemlerinin kullanılması gerekmektedir. Dünya genelinde enerjiye olan talep artışı, dağıtım ağlarının genişletilmesini önemli kılmaktadır. Yenilenebilir enerji maliyetleri yüzünden enerji sistemlerinin uzun dönemli planlamasında ve tasarımında en iyiyi seçmek için karar verilmektedir.

Bazı araştırmacılar aralıklı doğrusal programlama, şans-kısıtlı programlama ve karma tamsayılı programlama tekniklerini arzu edilen enerji kaynak/ hizmet atanmasında ve en küçük sistem maliyeti ile kapasite genişletme planlarında, en büyük sistem güvenirliğinde ve enerji güvenliğinde uygulamaktadırlar (Cai vd., 2009). Soroudi vd. (2011) dağıtım ağları için dağıtık enerji seçeneklerinin yanında uzun vadeli çok amaçlı dinamik programlama modelini GA kullanarak maliyetleri ve optimal büyüklükteki tasarımların kararlaştırılmasında kullanmıştır.

Bazı araştırmacılar karbon emisyonu ticaret programı altında güç iletim ağlarının en küçük maliyetli çözümünde karma tamsayılı programlama modeli, GA, tavlama benzetimi ve TA yöntemlerini kullanmışlardır (Sadegheih, 2011). Zangeneh vd. (2009), bazı nesil teknolojileri düşünerek optimal planlama projeleri için pareto tabanlı çok amaçlı optimizasyon kullanmışlardır. Cai vd. (2009) çeşitli ekonomik ve sistem güvenirliği kısıtları altında karar alternatiflerinin verilmesine yardımcı olmak için uzun dönemli yenilenebilir enerji yönetim planlamasında tamsayılı doğrusal programlama, iki seviyeli programlama ve üstünlük-aşağılık tabanlı bulanık stokastik programlama modelini önermiştir.

Bazı belirsizliklerin varlığı yüzünden kısa vadeli enerji planları için yeni optimizasyon tekniklerinin önemi artmaktadır. Fleten vd. (2007) yenilenebilir üretimin geniş ölçekli senaryolarında rüzgar, güneş ve su gücü mevcudiyetinin rassallığı ve değişkenliğin etkisini telafi etmek için uygun optimizasyon modeli kullanmıştır. Hiremath vd. (2007) YSA kullanarak enerji talep tahmini yapan optimizasyon tekniği kullanmışlardır. Bazı araştırmacılar çizelgeleme ve işgücü çizelgeleme gibi gerçek problemde mükemmel sonuçlar almak için önişleme teknikleri ve sezgisel algoritmaları kullanmaktadır (Alvarez-Valdes vd.,2008).

Enerji planlama problemleri çoklu karar verici ve çoklu kriterler yöntemleriyle daha da komplekstir. Literatürde yenilenebilir enerji problemlerinde uygulanan bazı çok kriterli karar verme yöntemleri vardır (Pohekar ve Ramachandran, 2004; Wang vd., 2009). Niknam ve Firouzi (2009), Nelder-Mead Simpleks ve PSO hibridi ile yapılan yöntemin diğer populasyon tabanlı yöntemlerden daha iyi sonuç verdiğini göstermişlerdir. Niknam vd. (2010), GA, PSO, KKA ve Tabu Arama (TA) ile karşılaştırıldığında daha iyi sonuçlar verdiğinden yakıt hücre güç santrali içeren dağıtım ağlarının optimal operasyon yönetimini çözmek için bulanık adaptif PSO önermişlerdir.

Mourmouris ve Potolias (2013) bölgesel düzeyde enerji planlaması ve yenilenebilir enerji kaynaklarının kullanılması için birden fazla kriter kullanan ÇKKV yöntemi önermişlerdir. Farklı yenilenebilir enerji kaynaklarına göre yapılan çalışmalarda kullanılan optimizasyon çalışmaları aşağıdaki başlıklarda sunulmuştur. Bazı çalışmalarda en uygun yenilenebilir enerji alternatifi belirlemek için bulanık tabanlı ÇKKV yöntemleri uygulamıştır. (Kahraman, Kaya ve Cebi, 2009; Kaya ve Kahraman, 2011).

\subsection{Rüzgar Enerjisinde Kullanılan Modeller}

Dünyada rüzgar enerjisi potansiyelini gösteren çok fazla çalışma vardır. Rüzgar gücündeki trendler, büyüyen küçük ölçekli şebekeye bağlı türbinleri ve dünyada çok daha geniş çeşitlilikte yer alan yeni rüzgar projelerini içermektedir. Li vd. (2010) uzun vadeli rüzgar hızı dağılımlarında Bayes yöntemini uygulamışlardır. Zhao vd. (2009) üretim maliyeti ve sistem güvenirliği bakımından rüzgar tarlalarının elektrik sistemi tasarımındaki girdilerin anahtar spesifikasyonlarını belirlemede GA'yı kullanmışlardır. Wen vd. (2015), enerji sistemi maliyetini en aza indirgemek ve sistem voltaj seviyesini iyileştirmek amacıyla depolama birimlerini konumlandırmak ve boyutlandırmak için üzgar enerjisi üretimindeki belirsizlikleri göz önüne alan bir çok amaçlı hibrid PSO yaklaşımı önermişlerdir.

Araştırmalarda rüzgar gücü ile ilgili önemli konu optimal rüzgar tarlası tasarımındaki rüzgar 
türbinlerinin tasarımı ve rüzgar tarlası yerleşimidir. Firmalar ortalama türbin boyutlarını ve teknolojilerini geliştirmeye çalışmaktadırlar. Benini ve Toffolo (2002), çok amaçlı evrimsel yaklaşımı ile rüzgar parkının metrekare başına toplam enerji üretimindeki en iyi performansı bulacak yatay eksenli rüzgar türbinlerinin rotor konfigürasyonunu bulacak geometrik parametre optimizasyonunda kullanmışlardır. Kusiak ve Zheng (2010) veri madenciliği ve evrimsel hesaplamayı birleştirerek rüzgar türbinleri tarafından üretilen gücü optimize etmişlerdir. Diğer yazarlar rüzgar hızı dağılımı ve güç-hız karakteristiklerinden kaynaklanan hesap belirsizliklerini dikkate alınarak optimum kapasite saptanması için karma tamsayılı doğrusal olmayan programlama modeli içeren bir karar analiz tekniği önermişlerdir (Kongnam vd., 2009). Zakariazadeh vd. (2014) yüksek rüzgâr gücü etkisiyle akıllı bir dağıtım sisteminde enerji ve rezervin çizelgelenmesi için stokastik çok amaçlı bir ekonomik / çevresel / operasyonel yöntem önerilmiştir.

Literatürde tahmin hassasiyetini artırmak için birçok rüzgar hızı tahmin algoritması önerilmiştir (Guo vd., 2011; Ren vd., 2014). Rüzgar mühendisliğindeki en önemli problemlerden biri rüzgar hızına ve sistem değerlerine bağlı olan rüzgar türbinlerinin çıktı verilerini tahmin etmektir. Bu durum araştırmacıların rüzgar türbini güç eğrisi tahminlemede bulanık mantık modelleme kullanmalarının nedeni olarak açıklanabilir (Üstüntaş ve Şahin, 2008). Grady vd. (2005) kurulu türbin sayısını sınırlandırarakmaksimum üretim kapasitesi için rüzgar türbinlerinin optimum yerleşimini belirlemek için bir GA sunmuştur. Gebraad vd. (2016) rüzgar santralinin iyileştirilmiş enerji üretimi için rüzgar türbinlerinin yalpalama ayarlarını optimize eden bir rüzgar santrali kontrol stratejisi sunmaktadırlar.

\subsection{Güneş Enerjisinde Kullanılan Modeller}

Güneş enerjisi, güneşin çekirdeğinde yer alan füzyon süreci ile açığa çıkan ışıma enerjisidir. Rüzgar enerjisi problemlerinde olduğu gibi güneş enerjisi santrali kurulum yeri seçimi önemli kararlardan biridir. Vafaeipour vd. (2014) güneş enerjisi santrallerinin kurulması için bölgelerin önceliklendirilmesi amacıyla ekonomik, çevresel, teknik, sosyal ve risk kriterlerini göz önünde bulunduran hibrit bir ÇKKV yaklaşımı uygulamışlardır. Omitaomu vd. (2012), yenilenebilir enerji kaynakları tesis yeri seçimi için Coğrafi Bilgi Sistemine (CBS) dayalı yeni bir yaklaşım önermişlerdir. Lozano vd. (2013), İspanya'nın bir bölgesinde fotovoltaik güneş enerjisi santrallerinin optimal yerleşiminin değerlendirilmesi için CBS ve ÇKKV yöntemlerinin kombinasyonunu önermişlerdir.

Diğer bir çalışma alanı güneş ışınım düzeyi tahmini çalışmalarıdır. Bosch vd. (2008) tek radyometrik istasyonu verilerini kullanarak karmaşık dağ arazi üzerinde güneş ışınım düzeylerini hesaplamak için YSA tabanlı bir yapay zeka tekniği sunmuşlardır. Güneş ışınımı tahmini için uygulanan diğer algoritmalar YSA (Cao ve Lin, 2008; Zervas vd., 2008) ve nöro-bulanık çıkarım sistemleridir (Mellit ve Kalogirou, 2011). Kalogirou vd. (2004) güneş enerji sistemini faydasını maksimize etmek için YSA ve GA kullanmışlardır. Ismail vd. (2013) fotovoltaik modül için geliştirilen modelinin parametrelerini elde etmek için GA'dan yararlanmışlardır.

Chang ve Ko (2009) güneş enerjisinden maksimum elektrik enerjisi sağlamak için nonlineer yapıyla birleştirilen PSO yaklaşımlı bir hibrid sezgiseli geliştirmişlerdir. Mellit vd. (2010) fotovoltaik sistemlerde YSA ve GA uygulamışlardır. Cirre vd. (2009) dağıtık güneş kolektör sahası kontrolü için bulanık mantık ve fiziksel model tabanlı iki yaklaşım geliştirmişlerdir.

\subsection{Hidroelektrik Enerjide Kullanılan Modeller}

Hidroelektrik enerji kaynağını nehirler oluşturmaktadır. Anagnostopoulos ve Papantonis (2007) hidroelektrik tesisinin optimal büyüklüğünü maksimum enerji ve ekonomik fayda sağlamak için stokastik bir evrimsel algoritma kullanmışlardır. Peña vd. (2009) zaman serileri tahmin yöntemini küçük bir su tesisinin kapasite tahmininde kullanmışlardır. Yoo (2009) lineer programlama yaklaşımıyla modelin duyarlılığını ve etkinliğini analiz eden hidroelektrik enerjisi üretimini en büyükleyen bir çalışma hazırlamıştır. Haddad vd. (2011) bal arısı optimizasyonu algoritması ile küçük hidroelektrik santrallerinin optimum tasarım, kontrol ve işletilmesi için bir stratejiyi ele almışlardır. De Ladurantate vd. (2009) barajlarda üretilen elektriğin satılmasıyla elde edilen karın maksimize edilmesi için deterministik ve stokastik modelleri analiz etmişlerdir. Kuby vd. (2005) stok kapasitesini artırmak ve su gücü kayıplarını azaltmak için nehir sistemindeki barajla ilgili ekolojik ve ekonomik ödünleşmeyi analiz etmek için çok amaçlı kombinatoryal yöntem kullanmışlardır. Finardi vd. (2005) sıralı kuadratik programlama ve lagranj gevşetmesi ile su termalleriyle bağlantılı su gücü tesislerinin çizelgesinin optimumluğunu bulmaya çalışmışlardır. Liu vd. (2009) orta dönemde akımların ve pazar fiyatlarının belirsizliği ile 
hidroelektrik porföy yönetimi için bir stokastik doğrusal programlama çatısı sunmuşlardır. PérezDíaz vd. (2010) hidroelektrik tesis için kısa dönemli işlemlerin güç dağılımı ve optimum birimlere karar veren bir nonlineer model uygulamışlardır. Huang vd. (2003) uzun dönemli su seviyesi tahminleri için YSA kullanmışlardır. Kazeminezhad vd. (2005) dalga parametrelerini tahmin etmek için adaptif ağ tabanlı bulanık sistem yaklaşımı geliştirmişlerdir. Reikard (2009) zaman değişimli regresyon modeliyle YSA'nı birleştirerek hibrid bir model ile okyanus dalgalarından kazanılacak enerjiyi tahmin etmek için zaman serileri modeli uygulamışlardır. Adhikary vd. (2015), hidroelektrik enerji projesi planlaması ve geliştirilmesi sürecinde hidrolik türbin seçimi için yeni bir ÇKKV yöntemi sunmuşlardır. Frijns vd. (2015), hidro enerji potansiyelinden daha iyi yararlanmak amacıyla optimum hidroelektrik performansı ve su temini hizmeti ile dengede olan çok amaçlı bir teknik önermişlerdir.

\subsection{Biyoenerjide Kullanılan Modeller}

Biyoenerji kaynağı biyolojik atıklardır. RecheLópez vd. (2009), biyokütle yakıtlı elektrik santrallerini yerleştirme ve tedarik alanlarını optimize etmek amacıyla çeşitli dört farklı meta sezgisel tekniği uygulamışlar ve sonuçları karşılaştırmışlardır. Bir diğer çalışmada biyokütle yakıtlı enerji santrallerinin yeri ve büyüklüğünün belirlenmesi amacıyla hibrid bir PSO yaklaşımı önerilmiştir (Gómez-González vd., 2013). Pantaleo vd. (2014) kentsel alanlardaki ISI ve enerji üretimi için çoklu biyokütle ve doğal gaz stratejik tedarik zinciri tasarımını optimize etmek amacıyla karma tamsayılı doğrusal programlama yaklaşımı sunmuşlardır.

Rentizelas vd. (2009) çoklu-biyokütle enerji dönüşüm uygulamalarını dikkate alarak çeşitli teknik, yasal, sosyal ve mantıksal kısıtlamalar altında bir optimizasyon yöntemi önermişlerdir. Madlener (2009) ekonomik ve çevre açısından göreceli performansını belirlemek için tarla biyogaz bitkilerinin büyük sayıda performansını değerlendirmek amacı ile çok kriterli bir yöntemle araştırma yapmıştır.

\subsection{Jeotermal Enerjide Kullanılan Modeller}

Jeotermal enerji kaynağı yer altı sularıdır. Bir jeotermal ısı pompası depolanan ısıyı kışın binaya transfer edebilir ve yazın binadan Isı aktarabilir (Omer, 2008). Dagdas (2007) yıllıknet karı maksimum yapacak bir optimizasyon modeli önermiştir. Tselepidou ve Katsifarakis (2010) hesaplanan yıllık maliyetler yardımıyla düşük entalpili jeotermal enerji sistemini
GA kullanarak hazırlamışlardır. Sener ve Van (2005) jeotermal enerji projesi değerlendirme teknikleri için bir literatür çalışması yayınlamışlardır. Sigurdardottir vd. (2015) operasyonel ve sürdürülebilirlik kısıtlarına sahip düşük sıcaklıktaki jeotermal kaynaklarını kullanarak mevcut kâr değerini optimize etmek için karma tam sayılı optimizasyon modeli önermişlerdir.

\subsection{Hibrid Sistemlerde Kullanılan Modeller}

Birden çok enerji kaynağı kullanılarak oluşturulan enerji sistemlerine hibrid enerji sistemleri denir. Fotovoltaik güneş panellerinin ve rüzgar türbinlerinin enerji üretimi iklim şartlarına göre değiştiğinden ayrı ayrı kullanıldıklarında çok etkin değillerdir. Rüzgar ve güneş enerji sistemleri birleştirilerek daha etkin hibrid sistemler oluşturulur.

Pereira vd. (2016) termik ve yenilenebilir enerji santrallerini entegre edebilen bir elektrik planlama modeli önermişlerdir. Karışık bir hidro-termik-rüzgar enerjisi sistemi için farklı elektrik senaryolarının analizi, önerilen karma tamsayı optimizasyon modeli kullanılarak sunulmuştur. Katsigiannis vd. (2010) sistemdeki gaz emisyonlarını en küçüklerken enerji maliyetini de en küçükleyen çok amaçlı bir algoritma kullanmışlardır. Ould vd. (2010) en az kayıpla güç tedariği ve en küçük maliyetle bir hibrid güneş-rüzgar bataryası için Pareto çok amaçlı GA önermişlerdir. Montoya vd. (2010) güç ağlarındaki kayıpları ve voltaj sapmalarını en küçüklemek için bir Pareto çok amaçlı metasezgisel önermişlerdir. Lagorse vd. (2009) tek başına sokak aydınlatma sistemi için fotovoltaik, pil ve bir yakıt hücresini bağlayan bir hibrid sistemi optimize etmek için GA ve simpleks algoritması uygulamışlardır. Eke. vd. (2005) aylık ortalama güneş ışınımı ve rüzgar hızı verilerini dikkate alarak elektrik tüketimini karşılamak için bir rüzgar-fotovoltaik hibrid sistem tasarımı için bir optimizasyon yöntemi sunmuştur. Giannakoudis vd. (2010) hibrid bir enerji üretim sisteminin tasarımı ve işletilmesi için optimizasyon yöntemi önermiştir. Stoppato vd. (2014) PSO'ya dayanan bir optimizasyon modeli sayesinde, kullanıcıların gereksinimlerini karşılamak ve sistem verimliliğini artırmak için küçük bir köyde elektrik ve su tedarik etmeyi amaçlayan bir sistem önermişlerdir. Bernal-Agustin ve Dufo-López (2009) karmaşık bir fotovoltaik-rüzgar-dizel-batarya-hidrojen sisteminden oluşan elektrik enerjisi üretiminde bir hibrid sistemin verimli tasarımı ve kontrolü için bir evrimsel algoritma sunmuşlardır. Chakraborty vd. (2009) rüzgar ve güneş enerji sistemleri ile entegre termik ünitelerin planlama sorunlarını çözmek için GA ve PSO uygulamışlardır. 
Hibrid enerji modellerine en iyi örnek pompaj depolamalı hidroelektrik santrallerdir. Bu alanda literatürde bir çok çalışma bulunmaktadır (J.S. Anagnostopoulos ve Papantonis, 2008; Bozorg, vd., 2014). Papaefthymiou ve Papathanassiou (2014) bir ada üzerinde çalışan pompaj depolamalı hibrit enerji santralinde (hidro türbinler, pompalar, rüzgar tarlaları) GA'dan yararlanarak optimum boyutlandırmayı araştırmışlardır.

$\mathrm{Bu}$ bölümde sunulan çalışmalar Tablo 2'de özetlenmektedir.

Tablo 2: Literatür Araştırması

\begin{tabular}{|c|c|c|c|c|}
\hline & Yazar(lar) & Yıl & Problem & Çözüm Yöntemi \\
\hline \multirow{14}{*}{$\begin{array}{l}\bar{\Phi} \\
\stackrel{\bar{U}}{\circlearrowleft}\end{array}$} & $\begin{array}{l}\text { Mourmouris ve } \\
\text { Potolias }\end{array}$ & 2013 & $\begin{array}{l}\text { Yenilenebilir enerji kaynakları } \\
\text { planlaması }\end{array}$ & ÇKKV yöntemi \\
\hline & Soroudi vd. & 2011 & Dağıtık ağ planlama modeli & Çok amaçı ı dinamik programlama, GA \\
\hline & Niknam vd. & 2010 & $\begin{array}{l}\text { Yakıt güç santrali içeren dağıtım } \\
\text { ağlarının optimal operasyon } \\
\text { yönetimi }\end{array}$ & Bulanık adaptif PSO \\
\hline & Sadegheih & 2010 & $\begin{array}{l}\text { Sistem iletim ağlarının en küçük } \\
\text { maliyetle optimal tasarım } \\
\text { yöntemleri }\end{array}$ & $\begin{array}{l}\text { Karma tam sayılı model, GA, tavlama } \\
\text { benzetimi, tabu arama }\end{array}$ \\
\hline & Cai vd. & 2009 & $\begin{array}{l}\text { Enerji kaynak planlaması, enerji } \\
\text { sistem tahmini }\end{array}$ & $\begin{array}{l}\text { Aralıklı doğrusal programlama, Karma } \\
\text { tamsayılı programlama, Şans-kısıtlı } \\
\text { programlama }\end{array}$ \\
\hline & Zanenah vd. & 2009 & Optimal planlama projeleri & $\begin{array}{l}\text { Pareto tabanlı çok amaçlı } \\
\text { optimizasyon }\end{array}$ \\
\hline & Cai vd. & 2009 & $\begin{array}{l}\text { Sistem güvenirliği kısıtları altında } \\
\text { karar alternatiflerinin verilmesi }\end{array}$ & $\begin{array}{l}\text { Tam sayılı programlama, iki seviyeli } \\
\text { bulanık stokastik programlama }\end{array}$ \\
\hline & Kahraman vd. & 2009 & $\begin{array}{l}\text { En uygun yenilenebilir enerji } \\
\text { alternatifi belirlemek }\end{array}$ & ÇÖKV yöntemi \\
\hline & Wang vd. & 2009 & $\begin{array}{l}\text { Enerji planlamasında çok kriterli } \\
\text { karar verme }\end{array}$ & ÇKKV yöntemi \\
\hline & Alvarez vd. & 2009 & $\begin{array}{l}\text { Enerji sistemlerinde işgücü } \\
\text { çizelgeleme }\end{array}$ & Sezgisel algoritmalar \\
\hline & $\begin{array}{l}\text { Niknam ve } \\
\text { Frouzi }\end{array}$ & 2009 & Enerji dağıtım durum tahmini & $\begin{array}{l}\text { Hibrit Nelder-Mead simpleks } \\
\text { algoritması ve PSO }\end{array}$ \\
\hline & Loken E. & 2007 & $\begin{array}{l}\text { Enerji planlamasında çok kriterli } \\
\text { karar verme }\end{array}$ & ÇKKV yöntemi \\
\hline & Hremath vd. & 2007 & $\begin{array}{l}\text { Enerji talep tahmini yapan } \\
\text { optimizasyon tekniği }\end{array}$ & YSA \\
\hline & Pohekar vd. & 2004 & $\begin{array}{l}\text { Enerji planlamasında çok kriterli } \\
\text { karar verme }\end{array}$ & ÇKKV yöntemi \\
\hline \multirow{2}{*}{ 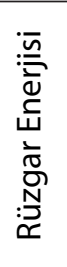 } & Gebraad vd. & 2016 & $\begin{array}{l}\text { rüzgar türbinlerinin yalpalama } \\
\text { ayarlarını optimizasyonu }\end{array}$ & $\begin{array}{l}\text { Simülasyon temelli optimizasyon } \\
\text { yöntemi }\end{array}$ \\
\hline & Wen & 2015 & $\begin{array}{l}\text { Rüzgar türbini için optimum } \\
\text { yerleşim ve boyutlandırma ile } \\
\text { enerji sistemi maliyetini en aza } \\
\text { indirgenmesi }\end{array}$ & Hibrid PSO taklaşımı \\
\hline
\end{tabular}


Tablo 2 (devam): Literatür Araştırması

\begin{tabular}{|c|c|c|c|c|}
\hline & Yazar(lar) & Yıl & Problem & Çözüm Yöntemi \\
\hline \multirow{10}{*}{ 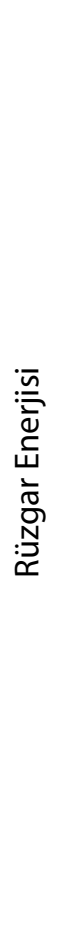 } & Zakariazadeh vd. & 2014 & $\begin{array}{l}\text { Akıllı bir dağıtım sisteminde enerji ve } \\
\text { rezervin çizelgelenmesi }\end{array}$ & $\begin{array}{l}\text { stokastik çok amaçlı } \\
\text { matematiksel yöntem }\end{array}$ \\
\hline & Ren vd. & 2014 & Rüzgar hızı tahmini & Sinir ağı tabanlı PSO \\
\hline & Guo vd. & 2011 & Rüzgar hızı tahmini & YSA \\
\hline & Lì vd. & 2010 & Rüzgâr hızı dağılımı & Bayes yöntemi \\
\hline & Kusiak ve Zheng & 2010 & $\begin{array}{l}\text { Rüzgâr türbini üretim gücü } \\
\text { optimizasyonu }\end{array}$ & $\begin{array}{l}\text { Veri madenciliği, evrimsel } \\
\text { hesaplama }\end{array}$ \\
\hline & Kongnam & 2009 & $\begin{array}{l}\text { Rüzgar hızı belirlemede optimum } \\
\text { kapasitenin saptaması }\end{array}$ & $\begin{array}{l}\text { Karma tamsayılı model } \\
\text { yaklaşımıyla bir karar analiz } \\
\text { tekniği }\end{array}$ \\
\hline & Zhao vd. & 2009 & Rüzgâr tarlaları elektrik sistem tasarımı & GA \\
\hline & Üstüntaş & 2008 & Rüzgâr türbini güç eğrisi tahmini & Bulanık mantık \\
\hline & Grady vd. & 2005 & $\begin{array}{l}\text { Rüzgar türbini için optimum yerleşim } \\
\text { tasarımı }\end{array}$ & GA \\
\hline & Benini ve Toffolo & 2002 & Rüzgâr parkında parametre tahmini & Çok amaçlı evrimsel yaklaşım \\
\hline \multirow{11}{*}{ 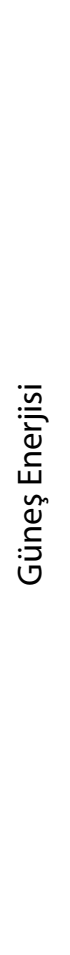 } & Vafaeipour vd. & 2014 & Santral yeri seçimi & ÇKKV yöntemi \\
\hline & Lozano & 2013 & $\begin{array}{l}\text { Fotovoltaik güneş enerjisi santrallerinin } \\
\text { optimal yerleşiminin değerlendirilmesi }\end{array}$ & CBS'ye dayalı ÇKKV yaklaşımı \\
\hline & Ismail vd. & 2013 & Parametre tahmini & GA \\
\hline & Omitaomu vd. & 2012 & $\begin{array}{l}\text { Yenilenebilir enerji kaynağı tesis yeri } \\
\text { seçimi }\end{array}$ & CBS'ye dayalı ÇKKV yaklaşımı \\
\hline & Mellit vd. & 2010 & Fotovoltaik sistemler & YSA, GA \\
\hline & Chang ve Ko & 2009 & Maksimum elektrik enerjisi sağlama & $\begin{array}{l}\text { Doğrusal olmayan model ve } \\
\text { PSO ile hibrid bir sezgisel }\end{array}$ \\
\hline & Cirre ve ark & 2009 & Dağıtık güneş kolektör saha kontrolü & Bulanık mantık \\
\hline & Bosch vd. & 2008 & Güneş radyasyon düzey hesaplaması & YSA \\
\hline & Cao, Zervas vd. & 2008 & Güneş ışınım tahmini & YSA, GA \\
\hline & Mellit vd. & 2008 & Güneş ışınımı tahmini & ANFIS \\
\hline & Kalogirou ve ark & 2004 & Güneş enerjisi sitemi optimizasyonu & YSA, GA \\
\hline
\end{tabular}


Tablo 2 (devam): Literatür Araştırması

\begin{tabular}{|c|c|c|c|c|}
\hline \multicolumn{2}{|r|}{ Yazar(lar) } & Yıl & Problem & Çözüm Yöntemi \\
\hline \multirow{14}{*}{ 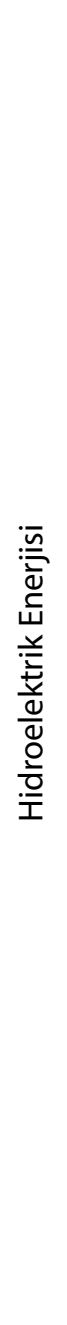 } & Adhikary vd & 2015 & Hidrolik türbin seçimi & ÇKKV yöntemi \\
\hline & Frijns vd. & 2015 & $\begin{array}{l}\text { Optimum hidr-enerji } \\
\text { potansiyelinin belilenmesi }\end{array}$ & Çok amaçlı yaklaşım \\
\hline & Haddad vd. & 2011 & $\begin{array}{l}\text { Hidroelektrik santrallerinin } \\
\text { optimum tasarım, kontrol ve } \\
\text { işletilmesi }\end{array}$ & Bal arısı optimizasyonu \\
\hline & Pérez-Díaz vd. & 2010 & $\begin{array}{l}\text { Hidroelektrik tesisinde güç } \\
\text { dağılımı }\end{array}$ & Doğrusal olmayan model \\
\hline & Pena vd. & 2009 & Kapasite tahmini & Zaman serileri \\
\hline & Ladurantate vd. & 2009 & $\begin{array}{l}\text { Barajlardaki elektriğin satılmasıyla } \\
\text { maksimum karın elde edilmesi }\end{array}$ & $\begin{array}{l}\text { Deterministik ve stokastik } \\
\text { modeller }\end{array}$ \\
\hline & Liu vd. & 2009 & Hidroelektirik yönetimi & Stokastik doğrusal programlama \\
\hline & Yoo & 2009 & $\begin{array}{l}\text { Hidroelektirik enerji üretimi } \\
\text { verimliliği }\end{array}$ & Lineer programlama \\
\hline & Reikard & 2009 & $\begin{array}{l}\text { Okyanus dalgalarından kazanılacak } \\
\text { enerji tahmini }\end{array}$ & $\begin{array}{l}\text { Regresyon modeli ve YSA ile hibrid } \\
\text { birmodel }\end{array}$ \\
\hline & $\begin{array}{l}\text { Anagnostopoulos } \\
\text { ve Papantonis }\end{array}$ & 2007 & $\begin{array}{l}\text { Hidroelektrik santralinden } \\
\text { maksimum enerji elde edilmesi }\end{array}$ & Stokastik evrimsel algoritma \\
\hline & Finardi vd. & 2005 & $\begin{array}{l}\text { Su tesislerinin çizelgelenmesi } \\
\text { ile optimum enerji planının } \\
\text { sağlanması }\end{array}$ & $\begin{array}{l}\text { Sıralı kuadratik programlama ve } \\
\text { lagranj gevşetmesi }\end{array}$ \\
\hline & Kuby vd. & 2005 & Barajlarda stok kapasite artırımı & Çok amaçlı programlama \\
\hline & Kazeminezhad vd. & 2005 & Dalga parametrelerinin tahmini & $\begin{array}{l}\text { Adaptif ağ tabanlı bulanık sistem } \\
\text { yaklaşımı }\end{array}$ \\
\hline & Huag vd. & 2003 & Su seviyesi tahmini & YSA \\
\hline \multirow{5}{*}{ 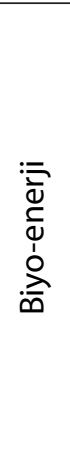 } & Pantaleo vd. & 2014 & $\begin{array}{l}\text { Biyokütle ve doğal gaz stratejik } \\
\text { tedarik zinciri tasarımı }\end{array}$ & $\begin{array}{l}\text { Karma tamsayılı doğrusal } \\
\text { programlama yaklaşımı }\end{array}$ \\
\hline & Gomez vd. & 2013 & $\begin{array}{l}\text { Biyo enerji santrallerinin yeri ve } \\
\text { büyüklüğünün belirlenmesi }\end{array}$ & Hibrid PSO \\
\hline & Madlener & 2011 & $\begin{array}{l}\text { Tarımsal biyogaz bitkilerinin } \\
\text { performansının değerlendirilmesi }\end{array}$ & ÇKKV yöntemi \\
\hline & Reche vd. & 2009 & $\begin{array}{l}\text { Dağıtık güç üretimi için biyoenerji } \\
\text { sistemlerinin optimum yer seçimi }\end{array}$ & GA \\
\hline & Rentizelas vd. & 2009 & $\begin{array}{l}\text { Multi-biyokütle enerji dönüşümü } \\
\text { için optimizasyon }\end{array}$ & Optimizasyon modeli \\
\hline
\end{tabular}


Tablo 2 (devam): Literatür Araştırması

\begin{tabular}{|c|c|c|c|c|}
\hline & Yazar(lar) & Yıl & Problem & Çözüm Yöntemi \\
\hline \multirow{4}{*}{ 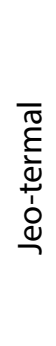 } & Sigurdardottir vd & 2015 & $\begin{array}{l}\text { Jeotermal kaynaklar kullanarak } \\
\text { mevcut kârın optimizasyonu }\end{array}$ & Karma tamsayılı model \\
\hline & $\begin{array}{l}\text { Tselepidou ve } \\
\text { Katsifarakis }\end{array}$ & 2010 & $\begin{array}{l}\text { Düşük entalpili enerji sistemi } \\
\text { optimizasyonu }\end{array}$ & GA \\
\hline & Omer & 2008 & Jeotermal ısı aktarımı & \\
\hline & Dagdas & 2007 & Net karın maksimizasyonu & Matematiksel model \\
\hline \multirow{13}{*}{ 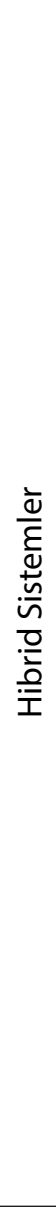 } & Pereira vd. & 2016 & $\begin{array}{l}\text { Termik ve yenilenebilir enerji } \\
\text { santrallerinin entegrasyonu }\end{array}$ & $\begin{array}{l}\text { Karma tamsayılı programlama } \\
\text { modeli }\end{array}$ \\
\hline & Stoppato vd. & 2014 & $\begin{array}{l}\text { Hibrid hidro enerji santralinin } \\
\text { optimizasyonu }\end{array}$ & PSO yaklaşımı \\
\hline & Bozorg vd. & 2014 & $\begin{array}{l}\text { Pompaj depolamalı hidroelektrik } \\
\text { santral optmizasyonu }\end{array}$ & $\begin{array}{l}\text { Doğrusal olmayan programlama } \\
\text { modeli }\end{array}$ \\
\hline & $\begin{array}{l}\text { Papaefthymiou ve } \\
\text { Papathanassiou }\end{array}$ & 2014 & $\begin{array}{l}\text { Pompaj depolamalı hidroelektrik } \\
\text { santral optmizasyonu }\end{array}$ & GA \\
\hline & Katsigiannis vd. & 2010 & $\begin{array}{l}\text { Gaz emisyonu ve enerji maliyetini } \\
\text { en küçüklenmesi }\end{array}$ & Çok amaçlı bir GA \\
\hline & Ould vd. & 2010 & $\begin{array}{l}\text { Hibrid bir güneş-rüzgar batarya } \\
\text { sistem büyüklüğünün belirlenmesi }\end{array}$ & Pareto çok amaçlı GA \\
\hline & Giannakoudis vd. & 2010 & $\begin{array}{l}\text { Hibrid enerji üretim sisteminin } \\
\text { tasarımı ve işletilmesi }\end{array}$ & Matematiksel model \\
\hline & Montoya vd. & 2009 & $\begin{array}{l}\text { Güç ağlarındaki kayıpların ve voltaj } \\
\text { sapmaların en küçüklenmesi }\end{array}$ & $\begin{array}{l}\text { Pareto tabanlı çok amaçlı meta } \\
\text { sezgisel }\end{array}$ \\
\hline & Lagorse vd. & 2009 & Hibrid sistemin optimizasyonu & GA, simpleks yöntemi \\
\hline & $\begin{array}{l}\text { Bernal-Agustín ve } \\
\text { López }\end{array}$ & 2009 & $\begin{array}{l}\text { Hibrid sistemin verimli tasarımı ve } \\
\text { kontrolü }\end{array}$ & Evrimsel Algoritma \\
\hline & Chakraborty vd. & 2009 & Termik ünite planlama problemi & GA, PSO \\
\hline & $\begin{array}{l}\text { Anagnostopoulos } \\
\text { ve Papantonis }\end{array}$ & 2008 & $\begin{array}{l}\text { Pompaj depolamalı hidroelektrik } \\
\text { santral optmizasyonu }\end{array}$ & $\begin{array}{l}\text { Simülasyon temelli optimizasyon } \\
\text { yaklaşımı }\end{array}$ \\
\hline & Eke. vd. & 2005 & $\begin{array}{l}\text { Bir rüzgar-fotovoltaik hibrid sistem } \\
\text { tasarımı }\end{array}$ & Matematiksel model \\
\hline
\end{tabular}

\section{SONUÇ}

Bu çalışmada enerji sektöründe ele alınan çeşitli problemler optimizasyon modelleri altında incelenerek sınıflandırılmış ve genel çerçeve literatür araştırması ile sunulmuştur. Literatürde yapılan çalışmalar incelendiğinde enerji üzerine yapılan çalışmaların büyük çoğunluğunu farklı disiplinlerden araştırmacılar tarafından ele alındığı görülmektedir. Enerjinin optimizasyonda uygulanabilecek geniş bir uygulama sahası mevcuttur. Enerji ile ilgili çalışmalar yüksek karmaşıklık ve belirsizlik içermesine rağmen literatürde stokastik ve bulanık modellere çok az rastlanmıştır. Ayrıca matematiksel modelin oluşturulmasının zor olduğu durumlarda benzetim uygulamaları karar vericiler için çok kullanışlı bir araç olabilir.

Enerji problemleri yüksek karmaşıklık içermesi ve birden çok amaca hizmet etmesi nedeniyle ÇAKV ve Pareto optimal yaklaşımların literatürde sıkça tercih edildiği görülmüştür. Enerji problemlerinin NP-zor olması nedeniyle karmaşık yapıdaki bu modeller için makul sürede çözüm sunan sezgisel yaklaşımlar kullanılmaktadır. Gerçek vaka analizleri bakımından ele alındığında literatürde nükleer santral ile ilgili 
çalışmalara az sayıda rastlanmıştır. Gelecekte enerji yatırımlarının büyük kısmını oluşturacağı öngörülen nükleer santrallerle ilgili daha çok çalışmaya yer verilebilir ve risk dereceleri, katkı dereceleri, enerji miktarları açısından analizler yapılabilir. Özellikle ülkemizde yenilenebilir enerji kaynaklarına olan

\section{KAYNAKLAR}

Adhikary, P., Roy, P. K. ve Mazumdar, A. (2015) “ Turbine supplier selection for small hydro project: Application of multi-criteria optimization technique" International Journal of Applied Engineering Research, 10(5), 13109-13122.

Alvarez-Valdes, R., Crespo, E., Tamarit, J. M. ve Villa, F. (2008) " GRASP and path relinking for project scheduling under partially renewable resources" European Journal of Operational Research, 189(3), 1153-1170. doi:10.1016/j.ejor.2006.06.073

Anagnostopoulos, J. S. ve Papantonis, D. E. (2007) “ Optimal sizing of a run-of-river small hydropower plant" Energy Conversion and Management, 48(10), 2663-2670. doi:10.1016/j.enconman.2007.04.016

Anagnostopoulos, J. S. ve Papantonis, D. E. (2008) "Simulation and size optimization of a pumped-storage power plant for the recovery of wind-farms rejected energy" Renewable Energy, 33(7), 1685-1694. doi:10.1016/j. renene.2007.08.001

Bakır, M. A. ve Altunkaynak, B. (2003) "Tamsayılı programlama: teori, modeller ve algoritmalar” Ankara: Nobel Yayınları.

Baños, R., Manzano-Agugliaro, F., Montoya, F. G., Gil, C., Alcayde, A. ve Gómez, J. (2011) “ Optimization methods applied to renewable and sustainable energy: A review" Renewable and Sustainable Energy Reviews, 15(4), 1753-1766. doi:10.1016/j.rser.2010.12.008

Ben-Haim, Y. (2006) "Info-gap decision theory: decisions under severe uncertainty” 2. Edition, Amsterdam: Elsevier/Academic Press.

Benini, E. ve Toffolo, A. (2002) "Optimal Design of Horizontal-Axis Wind Turbines Using Blade-Element Theory and Evolutionary Computation" Journal of Solar Energy Engineering, 124(4), 357-363. doi:10.1115/1.1510868

Bernal-Agustín, J. L. ve Dufo-López, R. (2009) “ Efficient design of hybrid renewable energy systems using evolutionary algorithms" Energy Conversion and Management, 50(3), 479-489. doi:10.1016/j.enconman.2008.11.007 ilginin arttığı şu günlerde sürdürülebilir, güvenilir ve temiz optimal enerji kaynağı seçimi üzerine çalışmalar farklı enerji sahaları için artırılabilir. Ülkemizin enerji sektöründeki planlama ve uygulama eksikliği düşünüldüğünde bu alanda verilecek kararlar için analitik tekniklerin kullanımı kaçınılmaz olacaktır.

Bertsimas, D. ve Sim, M. (2004) "The Price of Robustness" Operations Research, 52(1), 35-53. doi:10.1287/ opre. 1030.0065

Bosch, J. L., López, G. ve Batlles, F. J. (2008) “ Daily solar irradiation estimation over a mountainous area using artificial neural networks" Renewable Energy, 33(7), 1622-1628. doi:10.1016/j.renene.2007.09.012

Bozorg, H., Ashofteh, P.-S., Rasoulzadeh-Gharibdousti, S. ve Mariño, M. A. (2014) “ Optimization model for design-operation of pumped-storage and hydropower systems" Journal of Energy Engineering, 140(2) “doi:10.1061/(ASCE)EY.1943-7897.0000169

Cai, Y. P., Huang, G. H., Tan, Q. ve Yang, Z. F. (2009) "Planning of community-scale renewable energy management systems in a mixed stochastic and fuzzy environment" Renewable Energy, 34(7), 1833-1847. doi:10.1016/j.renene.2008.11.024

Cai, Y. P., Huang, G. H., Yang, Z. F., Lin, Q. G. ve Tan, Q. (2009) “ Community-scale renewable energy systems planning under uncertainty-An interval chance-constrained programming approach" Renewable and Sustainable Energy Reviews, 13(4), 721-735. doi:10.1016/j.rser.2008.01.008

Cao, J. ve Lin, X. (2008) “ Study of hourly and daily solar irradiation forecast using diagonal recurrent wavelet neural networks" Energy Conversion and Management, 49(6), 1396-1406. doi:10.1016/j.enconman.2007.12.030

Chakraborty, S., Senjyu, T., Saber, A. Y., Yona, A. ve Funabashi, T. (2009) " Optimal Thermal Unit Commitment Integrated with Renewable Energy Sources Using Advanced Particle Swarm Optimization" IEEJ Transactions on Electrical and Electronic Engineering, 4(5), 609-617. doi:10.1002/tee.20453

Chang, Y.-P. ve Ko, C.-N. (2009) “ A PSO method with nonlinear time-varying evolution based on neural network for design of optimal harmonic filters" Expert Systems with Applications, 36(3, Part 2), 6809-6816. doi:10.1016/j.eswa.2008.08.007

Cirre, C. M., Berenguel, M., Valenzuela, L. ve Klempous, R. (2009) " Reference governor optimization and control of a distributed solar collector field" Euro- 
pean Journal of Operational Research, 193(3), 709-717. doi:10.1016/j.ejor.2007.05.056

Dagdas, A. (2007) “ Heat exchanger optimization for geothermal district heating systems: A fuel saving approach" Renewable Energy, 32(6), 1020-1032. doi:10.1016/j.renene.2006.03.008

Dantzig, G. B. (1955) “ Linear Programming under Uncertainty” Management Science, 1(3/4), 197-206.

De Ladurantaye, D., Gendreau, M. ve Potvin, J.-Y. (2009) "Optimizing profits from hydroelectricity production" Computers \& Operations Research, Scheduling for Modern Manufacturing, Logistics, and Supply Chains, 36(2), 499-529. doi:10.1016/j.cor.2007.10.012

Dufo-López, R., Bernal-Agustín, J. L., Yusta-Loyo, J. M., Domínguez-Navarro, J. A., Ramírez-Rosado, I. J., Lujano, J. ve Aso, I. (2011) " Multi-objective optimization minimizing cost and life cycle emissions of standalone PV-wind-diesel systems with batteries storage" Applied Energy, 88(11), 4033-4041. doi:10.1016/j. apenergy.2011.04.019

Eke, R., Kara, O. ve Ulgen, K. (2005) “Optimization of a Wind/PV Hybrid Power Generation System” International Journal of Green Energy, 2(1), 57-63. doi:10.1081/ GE-200051304

Finardi, E. C., da Silva, E. L. ve Sagastizábal, C. (2005) "Solving the unit commitment problem of hydropower plants via Lagrangian Relaxation and Sequential Quadratic Programming" Applied Mathematics, 24(3), 317-342. doi:10.1590/S0101-82052005000300001

Fleten, S.-E., Maribu, K. M. ve Wangensteen, I. (2007) “ Optimal investment strategies in decentralized renewable power generation under uncertainty" Energy, 32(5), 803-815. doi:10.1016/j.energy.2006.04.015

Frijns, J., Marchet, E. C., Carriço, N., Covas, D., Monteiro, A. J., Ramos, H. M., ... Makropoulos, C. (2015) " Management tools for hydro energy interventions in water supply systems" Water Practice and Technology, 10(2), 214-228. doi:10.2166/wpt.2015.024

Gebraad, P. M. O., Teeuwisse, F. W., van Wingerden, J. W., Fleming, P. A., Ruben, S. D., Marden, J. R. ve Pao, L. Y. (2016) "Wind plant power optimization through yaw control using a parametric model for wake effects-a CFD simulation study" Wind Energy, 19(1), 95-114. doi: $10.1002 /$ we. 1822

Giannakoudis, G., Papadopoulos, A. I., Seferlis, P. ve Voutetakis, S. (2010) “On the Systematic Design and Optimization under Uncertainty of a Hybrid Power Generation System Using Renewable Energy Sources and Hydrogen Storage" S. P. and G. B. Ferraris (Ed.), Computer Aided Chemical Engineering içinde, 20th European
Symposium on Computer Aided Process Engineering (C. 28, ss. 907-912), Elsevier. http:/www.sciencedirect.com/ science/article/pii/S157079461028152X adresinden erişildi.

Goldberg, D., Deb, K. ve Korb, B. (1989) “ Messy genetic algorithms: motivation, analysis, and first results" Complex Systems, (3), 493-530.

Gómez-González, M., López, A. ve Jurado, F. (2013) “ Hybrid discrete PSO and OPF approach for optimization of biomass fueled micro-scale energy system" Energy Conversion and Management, 65, 539-545. doi:10.1016/j. enconman.2012.07.029

Grady, S. A., Hussaini, M. Y. ve Abdullah, M. M. (2005) “ Placement of wind turbines using genetic algorithms" Renewable Energy, 30(2), 259-270. doi:10.1016/j.renene.2004.05.007

Guo, Z., Wu, J., Lu, H. ve Wang, J. (2011) “A case study on a hybrid wind speed forecasting method using BP neural network" Knowledge-Based Systems, 24(7), 1048-1056. doi:10.1016/j.knosys.2011.04.019

Haddad, O., Moradi-Jalal, M. ve Mariño, M. A. (2011) “ Design-operation optimisation of run-ofriver power plants" Proceedings of the Institution of Civil Engineers - Water Management, 164(9), 463-475. doi:10.1680/wama.2011.164.9.463

Hiremath, R. B., Shikha, S. ve Ravindranath, N. H. (2007) “Decentralized energy planning; modeling and application-a review" Renewable and Sustainable Energy Reviews, 11(5), 729-752. doi:10.1016/j.rser.2005.07.005

Huang, W., Murray, C., Kraus, N. ve Rosati, J. (2003) "Development of a regional neural network for coastal water level predictions" Ocean Engineering, 30(17), 2275-2295. doi:10.1016/S0029-8018(03)00083-0

Iqbal, M., Azam, M., Naeem, M., Khwaja, A. S. ve Anpalagan, A. (2014) "Optimization classification, algorithms and tools for renewable energy: A review" Renewable and Sustainable Energy Reviews, 39, 640-654. doi:10.1016/j.rser.2014.07.120

Ismail, M. S., Moghavvemi, M. ve Mahlia, T. M. I. (2013) " Characterization of PV panel and global optimization of its model parameters using genetic algorithm" Energy Conversion and Management, 73, 10-25. doi:10.1016/j.enconman.2013.03.033

Jebaraj, S. ve Iniyan, S. (2006) “A review of energy models" Renewable and Sustainable Energy Reviews, 10(4), 281-311. doi:10.1016/j.rser.2004.09.004

Kahraman, C., Kaya, İ. ve Cebi, S. (2009) “ A comparative analysis for multiattribute selection among renewable energy alternatives using fuzzy axiomatic design and fuzzy analytic hierarchy process" Energy, 11th 
Conference on Process Integration, Modelling and Optimisation for Energy Saving and Pollution Reduction, 34(10), 1603-1616. doi:10.1016/j.energy.2009.07.008

Kalogirou, S. A. (2004) "Optimization of solar systems using artificial neural-networks and genetic algorithms" Applied Energy, 77(4), 383-405. doi:10.1016/ S0306-2619(03)00153-3

Katsigiannis, Y. A., Georgilakis, P. S. ve Karapidakis, E. S. (2010) "Multiobjective genetic algorithm solution to the optimum economic and environmental performance problem of small autonomous hybrid power systems with renewables" IET Renewable Power Generation, 4(5), 404-419. doi:10.1049/iet-rpg.2009.0076

Kaya, T. ve Kahraman, C. (2011) “ Multicriteria decision making in energy planning using a modified fuzzy TOPSIS methodology" Expert Systems with Applications, 38(6), 6577-6585. doi:10.1016/j.eswa.2010.11.081

Kazeminezhad, M. H., Etemad-Shahidi, A. ve Mousavi, S. J. (2005) “ Application of fuzzy inference system in the prediction of wave parameters" Ocean Engineering, 32(14-15), 1709-1725. doi:10.1016/j. oceaneng.2005.02.001

Kleinpeter, M. (1995) "Energy planning and policy" Chichester, John Wiley \& Sons.

Kongnam, C., Nuchprayoon, S., Premrudeepreechacharn, S. ve Uatrongjit, S. (2009) “Decision analysis on generation capacity of a wind park" Renewable and Sustainable Energy Reviews, 13(8), 2126-2133. doi:10.1016/j.rser.2009.01.023

Kuby, M. J., Fagan, W. F., ReVelle, C. S. ve Graf, W. L. (2005) "A multiobjective optimization model for dam removal: an example trading off salmon passage with hydropower and water storage in the Willamette basin" $A d$ vances in Water Resources, 28(8), 845-855. doi:10.1016/j. advwatres.2004.12.015

Kusiak, A. ve Zheng, H. (2010) “ Optimization of wind turbine energy and power factor with an evolutionary computation algorithm" Energy, 35(3), 1324-1332. doi:10.1016/j.energy.2009.11.015

Lagorse, J., Paire, D. ve Miraoui, A. (2009) “ Sizing optimization of a stand-alone street lighting system powered by a hybrid system using fuel cell, PV and battery" Renewable Energy, 34(3), 683-691. doi:10.1016/j. renene.2008.05.030

Liu, H., Jiang, C. ve Zhang, Y. (2009) “ Portfolio management of hydropower producer via stochastic programming" Energy Conversion and Management, 50(10), 2593-2599. doi:10.1016/j.enconman.2009.06.010

Li, Y. F., Li, Y. P., Huang, G. H. ve Chen, X. (2010) " Energy and environmental systems planning under
uncertainty-An inexact fuzzy-stochastic programming approach" Applied Energy, 87(10), 3189-3211. doi:10.1016/j.apenergy.2010.02.030

Lozano, J. M. S., Teruel-Solano, J., Soto-Elvira, P. L. ve Socorro, G.-C. (2013) “ Geographical Information Systems (GIS) and Multi-Criteria Decision Making (MCDM) methods for the evaluation of solar farms locations: Case study in south-eastern Spain" Renewable and Sustainable Energy Reviews, 24, 544-556. doi:10.1016/j. rser.2013.03.019

Madlener, R., Antunes, C. H. ve Dias, L. C. (2009) “ Assessing the performance of biogas plants with multi-criteria and data envelopment analysis" European Journal of Operational Research, 197(3), 1084-1094. doi:10.1016/j. ejor.2007.12.051

Mellit, A. ve Kalogirou, S. A. (2011) “ ANFIS-based modelling for photovoltaic power supply system: A case study" Renewable Energy, 36(1), 250-258. doi:10.1016/j. renene.2010.06.028

Mellit, A., Kalogirou, S. A. ve Drif, M. (2010) “ Application of neural networks and genetic algorithms for sizing of photovoltaic systems" Renewable Energy, 35(12), 2881-2893. doi:10.1016/j.renene.2010.04.017

Montoya, F. G., Baños, R., Gil, C., Espín, A., Alcayde, A. ve Gómez, J. (2010) “Minimization of voltage deviation and power losses in power networks using Pareto optimization methods" Engineering Applications of Artificial Intelligence, Advances in metaheuristics for hard optimization: new trends and case studies, 23(5), 695-703. doi:10.1016/j.engappai.2010.01.011

Moore, R. E. (1966) “ Interval analysis” Englewood Cliffs: Prentice-Hall.

Mourmouris, J. C. ve Potolias, C. (2013) “ A multi-criteria methodology for energy planning and developing renewable energy sources at a regional level: A case study Thassos, Greece” Energy Policy, 52, 522-530. doi:10.1016/j.enpol.2012.09.074

Niknam, T. ve Firouzi, B. B. (2009) “ A practical algorithm for distribution state estimation including renewable energy sources" Renewable Energy, 34(11), 2309-2316.

Niknam, T., Firouzi, B. B. ve Ostadi, A. (2010) “A new fuzzy adaptive particle swarm optimization for daily Volt/Var control in distribution networks considering distributed generators" Applied Energy, 87(6), 1919-1928. doi:10.1016/j.apenergy.2010.01.003

Omer, A. M. (2008) “ Ground-source heat pumps systems and applications" Renewable and Sustainable Energy Reviews, 12(2), 344-371. doi:10.1016/j.rser.2006.10.003 
Omitaomu, O. A., Blevins, B. R., Jochem, W. C., Mays, G. T., Belles, R., Hadley, S. W., ... Rose, A. N. (2012) “ Adapting a GIS-based multicriteria decision analysis approach for evaluating new power generating sites" Applied Energy, 96, 292-301. doi:10.1016/j.apenergy.2011.11.087

Ould Bilal, B., Sambou, V., Ndiaye, P. A., Kébé, C. M. F. ve Ndongo, M. (2010) “ Optimal design of a hybrid solar-wind-battery system using the minimization of the annualized cost system and the minimization of the loss of power supply probability (LPSP) "Renewable Energy, 35(10), 2388-2390. doi:10.1016/j.renene.2010.03.004

Pantaleo, A. M., Giarola, S., Bauen, A. ve Shah, N. (2014) "Integration of biomass into urban energy systems for heat and power Part I: An MILP based spatial optimization methodology" Energy Conversion and Management, 83, 347-361. doi:10.1016/j.enconman.2014.03.050

Papaefthymiou, S. V. ve Papathanassiou, S. A. (2014) " Optimum sizing of wind-pumped-storage hybrid power stations in island systems" Renewable Energy, 64, 187-196. doi:10.1016/j.renene.2013.10.047

Peña, R., Medina, A., Anaya-Lara, O. ve McDonald, J. R. (2009) "Capacity estimation of a minihydro plant based on time series forecasting" Renewable Energy, 34(5), 1204-1209. doi:10.1016/j.renene.2008.10.011

Pereira, S., Ferreira, P. ve Vaz, A. I. F. (2016) “ Optimization modeling to support renewables integration in power systems" Renewable and Sustainable Energy Reviews, 55, 316-325. doi:10.1016/j.rser.2015.10.116

Pérez-Díaz, J. I., Wilhelmi, J. R. ve Sánchez-Fernández, J. Á. (2010) "Short-term operation scheduling of a hydropower plant in the day-ahead electricity market" Electric Power Systems Research, 80(12), 1535-1542. doi:10.1016/j.epsr.2010.06.017

Pohekar, S. D. ve Ramachandran, M. (2004) “Application of multi-criteria decision making to sustainable energy planning-A review" Renewable and Sustainable Energy Reviews, 8(4), 365-381. doi:10.1016/j. rser.2003.12.007

Reche-López, P., Ruiz-Reyes, N., García Galán, S. ve Jurado, F. (2009) " Comparison of metaheuristic techniques to determine optimal placement of biomass power plants" Energy Conversion and Management, 50(8), 2020-2028. doi:10.1016/j.enconman.2009.04.008

Reikard, G. (2009) “Forecasting ocean wave energy: Tests of time-series models" Ocean Engineering, 36(5), 348-356. doi:10.1016/j.oceaneng.2009.01.003

Ren, C., An, N., Wang, J., Li, L., Hu, B. ve Shang, D. (2014) "Optimal parameters selection for BP neural network based on particle swarm optimization: A case study of wind speed forecasting" Knowledge-Based Systems, 56, 226-239. doi:10.1016/j.knosys.2013.11.015

Rentizelas, A. A., Tatsiopoulos, I. P. ve Tolis, A. (2009) "An optimization model for multi-biomass tri-generation energy supply” Biomass and Bioenergy, 33(2), 223-233. doi:10.1016/j.biombioe.2008.05.008

Sadegheih, A. (2011) “ Optimal design methodologies under the carbon emission trading program using MIP, GA, SA, and TS" Renewable and Sustainable Energy Reviews, 15(1), 504-513. doi:10.1016/j.rser.2010.07.035

Savic, D. (2002) “Single-objective vs. Multiobjective Optimisation for Integrated Decision Support, In: Integrated Assessment and Decision" Proceedings of the First Biennial Meeting of the International Environmental Modelling and Software Society içinde (ss. 12-7) “

Scopus. (2016) “Scopus - Document search results" 23 Aralık 2016 tarihinde https:/www.scopus.com/ fields=TITLE_ABS_KEY=Multi+Objective+Decision +Making\%multi+objective+optimization\%multiple+objective+decision+making adresinden erişildi.

Sener, A. C. ve Van, D. (2005) “Evolution of techni$\mathrm{cal}$ and economical decision making in geothermal energy projects" Transactions - Geothermal Resources Council, C. 29, ss. 475-481.

Sigurdardottir, S. R., Valfells, A., Palsson, H. ve Stefansson, H. (2015) “ Mixed integer optimization model for utilizing a geothermal reservoir" Geothermics, 55, 171-181. doi:10.1016/j.geothermics.2015.01.006

Soroudi, A. ve Amraee, T. (2013) “ Decision making under uncertainty in energy systems: State of the art" Renewable and Sustainable Energy Reviews, 28, 376-384. doi:10.1016/j.rser.2013.08.039

Soroudi, A., Ehsan, M. ve Zareipour, H. (2011) “ A practical eco-environmental distribution network planning model including fuel cells and non-renewable distributed energy resources" Renewable Energy, 36(1), 179-188. doi:10.1016/j.renene.2010.06.019

Stoppato, A., Cavazzini, G., Ardizzon, G. ve Rossetti, A. (2014) "A PSO (particle swarm optimization)-based model for the optimal management of a small PV(Photovoltaic)-pump hydro energy storage in a rural dry area" Energy, 76, 168-174. doi:10.1016/j.energy.2014.06.004

Suganthi, L., Iniyan, S. ve Samuel, A. A. (2015) “ Applications of fuzzy logic in renewable energy systems A review" Renewable and Sustainable Energy Reviews, 48, 585-607. doi:10.1016/j.rser.2015.04.037

Taha, H. A. (2007) “ Yöneylem araştırması” (Ş. A. Baray ve Ş. Esnaf, Çev.) “ İstanbul: Literatür Yayıncıllk.

Talbi, E.-G. (2009) “ Metaheuristics: from design to implementation. Hoboken, N.J: John Wiley \& Sons. 
Tiryaki, A. E. ve Kazan, R. (2007) “ Bulaşık makinesinin bulanık mantık ile modellenmesi” Mühendis ve Makina, 48(565), 3-8.

TMMOB. (2012) “ Dünyada ve Türkiye'de Enerji Verimliliği ( No: 589)" Ankara: TMMOB Makine Mühendisleri Odası, http://www.mmo.org.tr/resimler/dosya_ekler/fa34c3c2eb9b729_ek.pdf adresinden erişildi.

Tselepidou, K. ve Katsifarakis, K. L. (2010) “ Optimization of the exploitation system of a low enthalpy geothermal aquifer with zones of different transmissivities and temperatures" Renewable Energy, Special Section: IST National Conference 2009, 35(7), 1408-1413. doi:10.1016/j.renene.2009.11.004

Turkay, M. (2006) “ Optimization Models and Solution Algorithms" New Frontiers in Total Quality and Strategic Management içinde . Ankara, Türkiye: Gazi Publishing.

Üstüntaş, T. ve Şahin, A. D. (2008) “Wind turbine power curve estimation based on cluster center fuzzy logic modeling" Journal of Wind Engineering and Industrial Aerodynamics, 96(5), 611-620. doi:10.1016/j. jweia.2008.02.001

Vafaeipour, M., Hashemkhani Zolfani, S., Morshed Varzandeh, M. H., Derakhti, A. ve Keshavarz Eshkalag, M. (2014) " Assessment of regions priority for implementation of solar projects in Iran: New application of a hybrid multi-criteria decision making approach" Energy Conversion and Management, 86, 653-663. doi:10.1016/j.enconman.2014.05.083

Wang, J.-J., Jing, Y.-Y., Zhang, C.-F. ve Zhao, J.-H. (2009) " Review on multi-criteria decision analysis aid in sustainable energy decision-making" Renewable and Sustainable Energy Reviews, 13(9), 2263-2278. doi:10.1016/j.rser.2009.06.021

Wen, S., Lan, H., Fu, Q., Yu, D. C. ve Zhang, L. (2015) “ Economic Allocation for Energy Storage System
Considering Wind Power Distribution" IEEE Transactions on Power Systems, 30(2), 644-652. doi:10.1109/ TPWRS.2014.2337936

Yoo, J.-H. (2009) “ Maximization of hydropower generation through the application of a linear programming model" Journal of Hydrology, 376(1-2), 182-187. doi:10.1016/j.jhydrol.2009.07.026

Zadeh, L. A. (1965) " Fuzzy sets" Information and Control, 8(3), 338-353. doi:10.1016/S00199958(65)90241-X

Zadeh, L. A. (2011) "A Note on Z-numbers" Information Sciences, 181(14), 2923-2932. doi:10.1016/j. ins.2011.02.022

Zakariazadeh, A., Jadid, S. ve Siano, P. (2014) “ Economic-environmental energy and reserve scheduling of smart distribution systems: A multiobjective mathematical programming approach" Energy Conversion and Management, 78, 151-164. doi:10.1016/j.enconman.2013.10.051

Zangeneh, A., Jadid, S. ve Rahimi-Kian, A. (2009) “ Promotion strategy of clean technologies in distributed generation expansion planning" Renewable Energy, 34(12), 2765-2773. doi:10.1016/j.renene.2009.06.018

Zervas, P. L., Sarimveis, H., Palyvos, J. A. ve Markatos, N. C. G. (2008) “Prediction of daily global solar irradiance on horizontal surfaces based on neural-network techniques" Renewable Energy, 33(8), 1796-1803. doi:10.1016/j.renene.2007.09.020

Zhao, M., Chen, Z. ve Blaabjerg, F. (2009) “ Optimisation of electrical system for offshore wind farms via genetic algorithm" IET Renewable Power Generation, 3(2), 205. doi:10.1049/iet-rpg:20070112

Zhou, P., Ang, B. W. ve Poh, K. L. (2006) “Decision analysis in energy and environmental modeling: An update" Energy, 31(14), 2604-2622. doi:10.1016/j. energy.2005.10.023 